OLFACTORY FUNCTION

The Influence of Demographic, Cognitive, and Genetic Factors

\title{
Margareta Hedner
}

Doctoral Thesis in Psychology at Stockholm University, Sweden 2013 



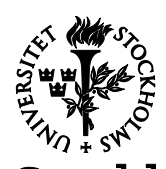

Stockholm

University

\section{Olfactory Function}

The Influence of Demographic, Cognitive, and Genetic factors

\section{Margareta Hedner}


(C) Margareta Hedner, Stockholm 2013

Cover illustration by Martin Wollerstam

ISBN 978-91-7447-628-6

Printed in Sweden by US-AB, Stockholm 2013

Distributor: The Department of Psychology, Stockholm University 



\section{Abstract}

Olfactory function is affected by demographic, cognitive, and genetic factors. In the present thesis, three empirical studies investigated individual differences in olfactory ability. Study I explored demographic and cognitive correlates in common olfactory tasks; odor detection, odor discrimination, and odor identification. The results indicated that old age influenced performance negatively in all tasks, and that semantic memory proficiency and executive functioning were related to odor discrimination and odor identification performance. No cognitive influence was observed for measurements of olfactory threshold. Using population-based data, Study II investigated a potential influence of the ApoE gene on olfactory identification after controlling for health status, semantic memory, and preclinical and clinical dementia. The main finding was that the ApoE- $\varepsilon 4$ allele interacted with age, such that older $\varepsilon 4$-carriers had an impaired odor identification performance relative to older non-carriers. Importantly, the negative ApoE- $\varepsilon 4$ effect on olfactory proficiency was independent of clinical dementia conversion within five years. Study III investigated the effects of the BDNF val66met polymorphism on olfactory change over a five-year interval, in a communitydwelling sample of young and old age cohorts. The results showed that agerelated decline in olfactory identification was influenced by the BDNF val66met. In middle-aged subjects, no effect of BDNF val66met was observed although older val homozygote carriers showed a selectively larger olfactory decline than the older met carriers. Overall, results suggest that the relative influence of demographic and cognitive factors vary across different olfactory tasks and that two genes (ApoE and BDNF) impact age-related deficits in odor identification. Potential theoretical and practical implications of the findings are discussed as well as potential limitations of association studies in genomics research.

Keywords: Olfaction, odor identification, odor threshold, odor discrimination, aging, gender, ApoE, BDNF, val66met, association study, populationbased 


\section{Acknowledgements}

First and foremost I am endlessly grateful to my main supervisor, Professor Maria Larsson. Your scientific advice and skills in olfaction and cognition have given me the confidence to work and grow as a researcher. Your networking skills, strong leadership, generosity, and stylishness are not only inspiring for conducting research but for life in general.

My second supervisor, Professor Lars-Göran Nilsson, thank you for introducing me to the Betula project, and for always being supportive and enthusiastic about my work.

Professor Thomas Hummel, thank you for kindly sharing your data and for introducing Dreseden as an exiting city, research-wise and socially. I hope there will be more collaboration in the future.

With smart and inspiring colleagues work is never boring! I would like to thank a whole bunch of people (in no particular order) for making the years as a PhD student into such a good time: Fredrik Jönsson, Johan Willander, Artin Arshamian, Stina Cornell Kärnekull, Veit Kubik, Ola Sternäng, Anna Sol Lindqvist, Cecilia Stenfors, Åke Wahlin, Martin Arvidsson, Jesper Alvarsson, Steven Nordin, Mats Olsson, Jonas Olofsson, Maria Rådsten Ekman, Mats Nilsson, Anders Sand, Nathalie Peira, Armita Golkar, Stefan Wiens, Anne Richter, Johanna Lovén, Håkan Andersson, Neda Kerimi, Emma Bäck, Marie Gustafsson Sendén, Gustaf Törngren, Mina Sedem, Farah Moniri, Tonya Pixton, Mats Englund, Kristina Karlsson, Jelena Corovic, Henry Montgomery, Torun Lindholm, Stephan Baraldi, Niklas Hansen, Lena Låstad, Hanna Kusterer, Roberto Riva, Lars Bergman, AnnCharlotte Smedler, Petra Lindfors, Lotta Lindqvist, Eva Persdotter, Ewa Sjöqvist, Britth Sandin, Elisabet Borg, Pehr Granqvist, Lars Nyberg, Martin Lövdén, Petter Marklund, Jonas Persson, and Tommy Olin.

During my thesis period I had the opportunity to spend a year at Columbia University, New York. Thank you Professor Dev Devanand for hosting me and taking the time to share your expertise, and thanks to the SverigeAmerika stiftelsen, Stockholm University, stiftelsen Lars Hiertas Minne, and stiftelsen Olle Engkvist Byggmästare for funding my stay. 
Dr Johan Lundström and Professor Ove Almkvist, your valuable input and comments have significantly improved the quality of this thesis. Thank you!

To my friends outside academia: you make me one lucky girl! Lena Hensvik and Isabel Schoultz (thanks for all adventures, sharp discussions, and our fantastic and long-lasting friendship) Aino Höglund and Sara Davidsson (thanks for your smartness, humor, and tender love in good times and in bad times), Nilspetter Westling, Helene Biller, Märta Nord, Sara Lindqvist, Camilla Granström, Mirjam Halldén, Anna Brolin, and Bokcirkeln (Lars Magnus Norén, Kajsa Eliasson, Herman Arfwedson, Robert Eriksson, and Erica Högsborn).

I also want to give a special thanks to my wonderful family: Marie-Louise Ekholm - for support and love throughout life, Thomas Hedner - for your never ending enthusiasm in my academic career and for your valuable advices, Erik Hedner - for your positive attitude and for always taking the time, Per Hedner - for your perceptiveness and tenderness, Kristina Hirschfeldt - for all your fun initiatives and tremendous love, Sten Hedner - for always believing in me, Nina Hedner - for support and encouragement, Ingrid Hedner and Dagny Elvstad - for all the good times, I miss you both, Benjamin Hedner, Anna Johansson, Gunnar Hirschfeldt, Anders Ekholm, Ingemar Hedner, Tore Hedner, and Johan Anderberg - for the food and all the tv-series, and alerting me on things happening in the outside world.

At last, Elin Hedner, you are the most important person in my life. Thank you for just being you! 


\section{List of studies}

The present thesis is based on the following studies:

1. Hedner, M., Larsson, M., Arnold, N., Zucco, G.M., \& Hummel, T. (2010). Cognitive factors in odor detection, odor discrimination, and odor identification tasks. Journal of Clinical and Experimental Neuropsychology, 32(10), 1062-1067.*

2. Olofsson, J.K., Nordin, S., Wiens, S., Hedner, M., Nilsson, L.-G., \& Larsson, M. (2010). Odor identification impairment in carriers of ApoE- $\varepsilon 4$ is independent of clinical dementia. Neurobiology of $\mathrm{Ag}$ ing, 31(4), 567-577.

3. Hedner, M., Nilsson, L., Olofsson, J.K., Bergman, O., Eriksson, E., Nyberg, L., \& Larsson, M. (2010). Age-related olfactory decline is associated with the BDNF val66met polymorphism: evidence from a population-based study. Frontiers in Aging Neuroscience, 2(24), 17.

* Paper I is printed with permission from Taylor \& Francis.

** Paper II is printed with permission from Elsevier. 


\section{Contents}

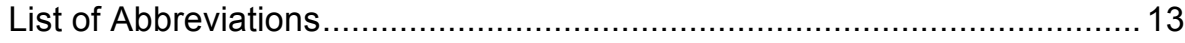

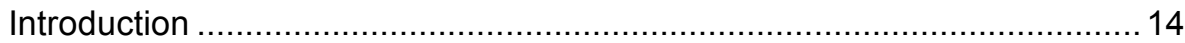

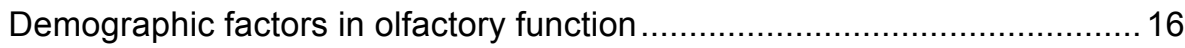

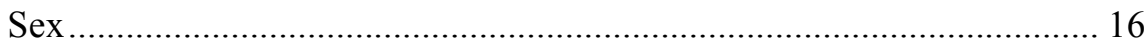

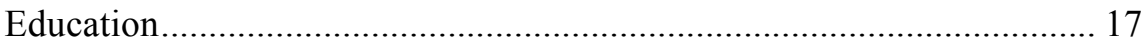

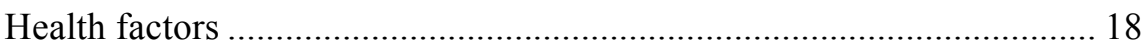

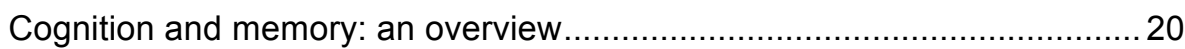

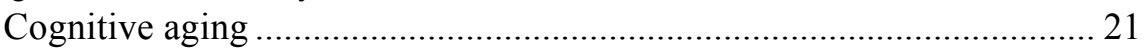

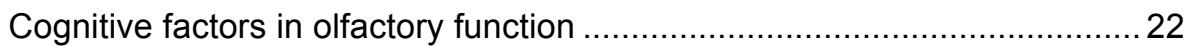

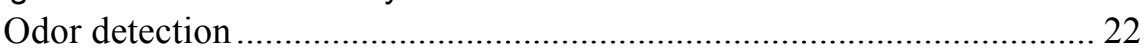

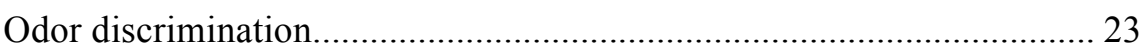

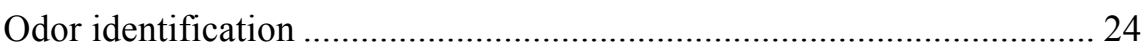

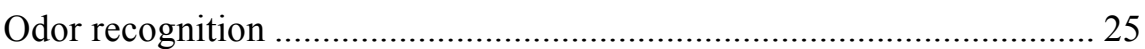

Relationships among olfactory tasks.................................................... 26

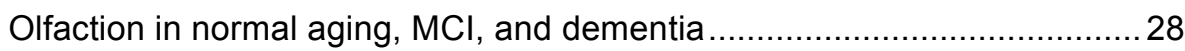

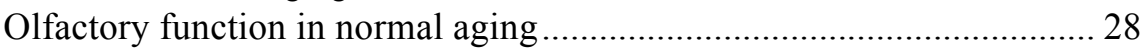

Olfactory function in MCI and dementia ............................................. 31

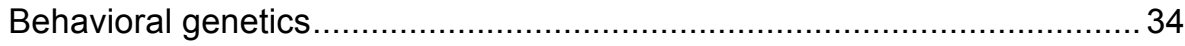

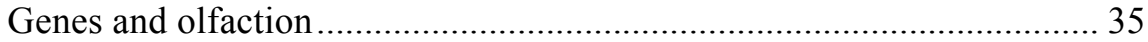

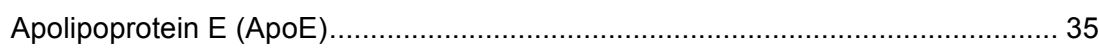

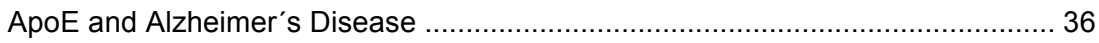

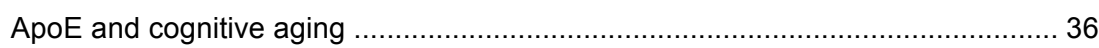

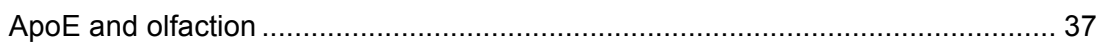

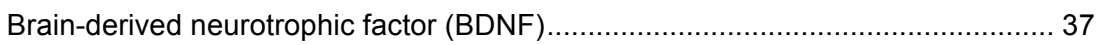

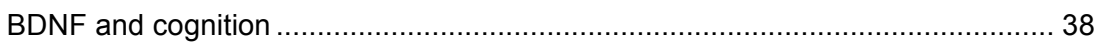

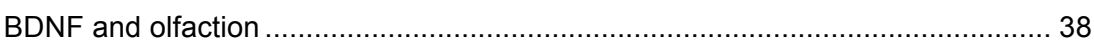

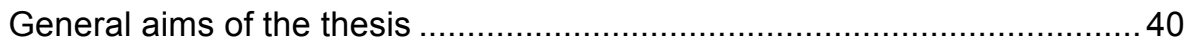

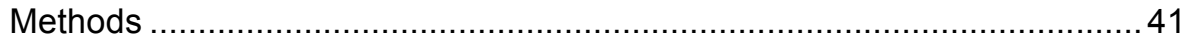

The Betula Prospective Cohort Study .................................................... 41

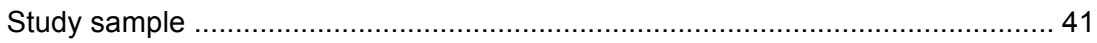

Assessment of olfactory function ............................................................. 42 


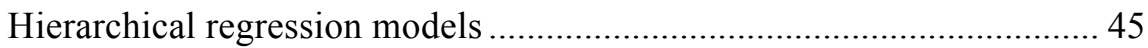

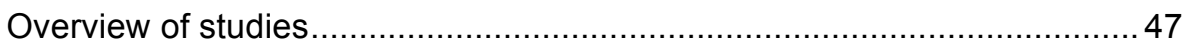

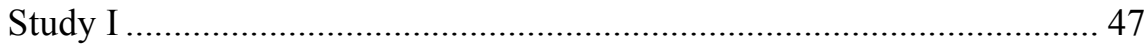

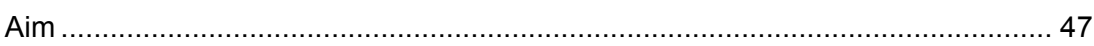

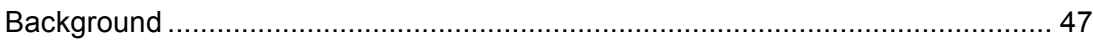

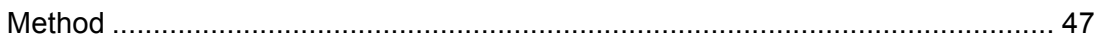

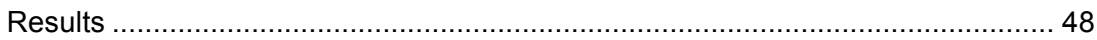

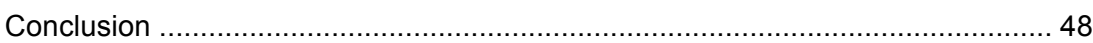

Study II ........................................................................ 50

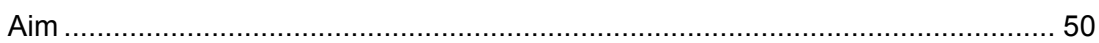

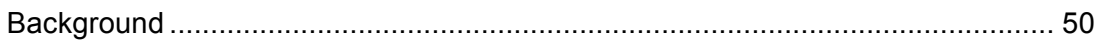

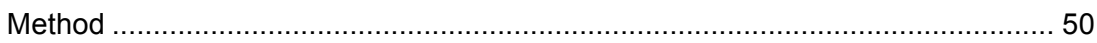

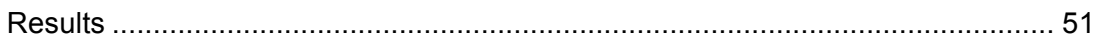

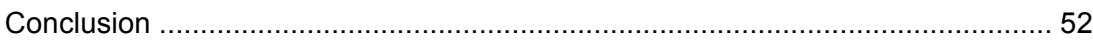

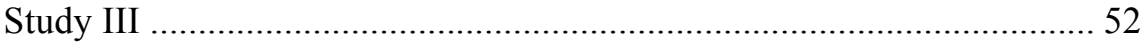

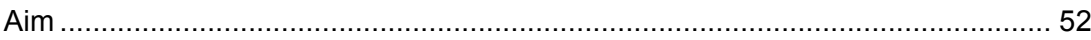

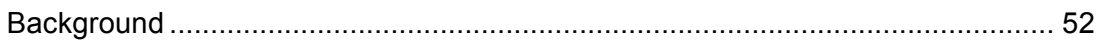

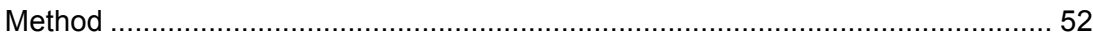

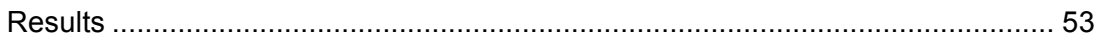

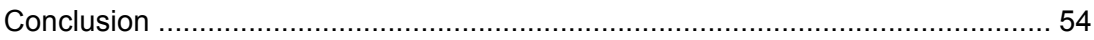

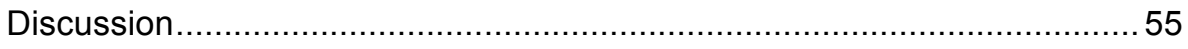

Influences of demographic variables on olfactory function...................... 56

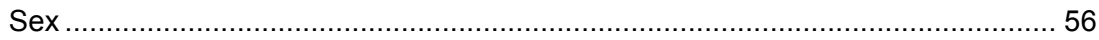

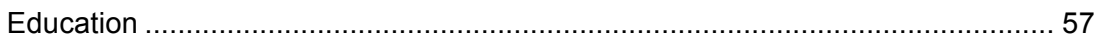

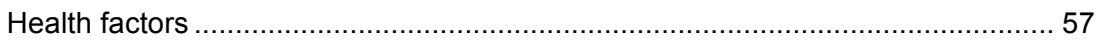

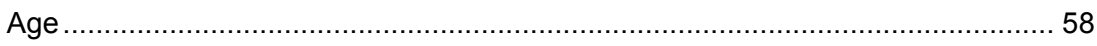

Influences of cognitive factors on olfactory tasks.................................... 58

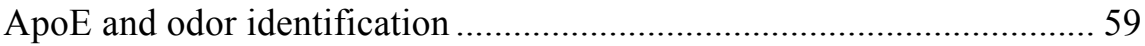

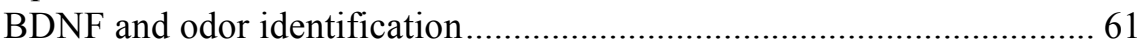

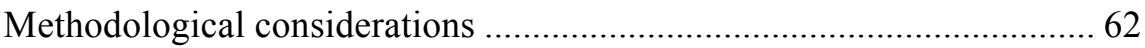

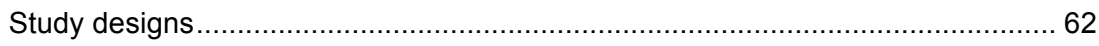

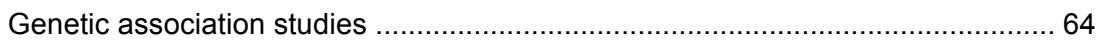

Suggestions for future studies ................................................65

Concluding remarks .............................................................. 66

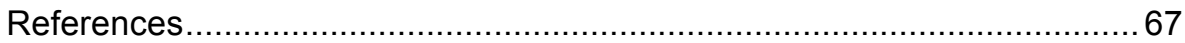




\section{List of Abbreviations}

\begin{tabular}{ll} 
Abbreviation & Full reference \\
\hline AD & Alzheimer's disease \\
BDoE & Apolipoprotein E \\
CNS & Brain-derived neurotrophic factor \\
ENT & Central nervous system \\
GCTA & Ear, nose, and throat \\
GWAS & Genome-wide complex-trait analysis \\
MCI & Genome-wide association study \\
MMSE & Mild cognitive impairment \\
ORN & Mini Mental State Examination \\
SEM & Olfactory receptor neuron \\
SMT & Structural equation model \\
SNP & Sniff Magnitude Test \\
SOIT & Single nucleotide polymorphism \\
& Scandinavian Odor Identification Test
\end{tabular}




\section{Introduction}

Sense of smell? I never gave it a thought. You don't normally give it a thought but when you lose it - it is like being struck blind or deaf. /.... You smell people, you smell books, you smell the city, you smell the spring - maybe not consciously but as a rich unconsciously background to anything else. My whole world was suddenly radically poorer. (Quote from a man who lost his sense of smell through a head injury, severely damaging his olfactory tracts in a novel by Oliver Sacks, "The man who mistook his wife for a hat", 1986).

We usually do not attend to odors unless we sense something out of the ordinary. However, when people loose their sense of smell they suddenly become aware of the important and qualitative role olfaction played in their life. Patients reporting persistent olfactory impairment after previously documented olfactory loss indicate a higher level of disability and lower quality of life (Deems et al., 1991; Hummel \& Nordin, 2005; Miwa et al., 2001). In addition, depression frequently accompanies the loss of smell and perception of flavour. Olfactory dysfunction is more widespread than believed. About $19 \%$ of adults (aged 20 years and older) in the Swedish population have an olfactory dysfunction (Brämerson, Johansson, Ek, Nordin, \& Bende, 2004). In the elderly, the prevalence rates are even higher: $24.5 \%$ for persons aged 53-97 years (Murphy et al., 2002). Surprisingly, self-reported olfactory impairments are relatively infrequent $(9.5 \%)$, indicating that olfactory testing is important for detection of olfactory deficits. As will be discussed later, several factors contribute to olfactory deficits, such as aging, various diseases (e.g., Alzheimer's disease) and genetic makeup.

The olfactory sense is our oldest sensory system, both phylogenetically and ontogenetically. Olfactory research has suggested that odor memory is distinct from memory for other sensory modalities, such as hearing or vision (Herz \& Engen, 1996; Richardson \& Zucco, 1989; Willander \& Larsson, 2006, 2007). Mothers and newborns identify each other by olfactory cues (Kaitz, Good, Rokem, \& Eidelman, 1987; Schaal et al., 1980). Also, humans can, by only using their sense of smell discriminate different age groups from each other (Mitro, Gordon, Olsson, \& Lundström, 2012).

Assessment of olfactory functions, such as detection (can you smell it?), discrimination (are these odors different?), odor identification (what's the 
name of this odor?), and odor recognition (have you smelled it before?) not only rely on sensory function but also depend on demographic and cognitive factors. In this thesis, I will investigate the role played by demographic, cognitive, and genetic factors on various olfactory tasks to provide a wider understanding of human olfactory function. 


\section{Demographic factors in olfactory function}

In order to accurately evaluate olfactory performance in population-based samples, several factors need to be taken into consideration. Evidence shows that individual variation in a range of demographic and health-related factors influence our sense of smell. Below, I review some of the demographic factors known to affect olfactory performance and that are highlighted in the studies that form the basis of this thesis. The most influential demographic factor affecting olfactory processing -chronological age- will be discussed in more detail in a separate section.

\section{Sex}

Current research indicates that sex is an important factor to consider when evaluating olfactory functions. Overall, studies show that females outperform men in most olfactory tasks (see Brand \& Millot, 2001 for a review). However, for odor sensitivity tasks (i.e., threshold), the pattern of findings is conflicting (Brand \& Millot, 2001). The National Geographic Smell Survey (1989) conducted by Wysocki and Gilbert revealed that women rated odors as more intense and also exhibited a higher detection accuracy. However, other studies found no support of a sex effect in odor thresholds (e.g., Segal, Topolski, Wilson, Brown, \& Araki, 1995; Öberg, Larsson, \& Bäckman, 2002). One reason for the mixed pattern of findings in odor sensitivity might be that the influence of sex varies as a function of the olfactory stimuli used and that different psychophysical methods have been applied in the threshold measurements (Koelega, 1994).

Few studies have investigated a potential sex effect in odor discrimination. Most evidence indicates no sex difference in quality discrimination (Kobal et al., 2000; Rabin, 1988). However, Pol, Hijman, Baaré, van Eekelen, and van Ree (2000) reported that young females had a slight advantage over men in an odor quality discrimination task, but this effect disappeared with increased task duration. In addition, Öberg, et al. (2002) investigated sex effects across a number of different olfactory tasks and found no reliable sex effects in intensity or quality discrimination. 
In contrast, a vast majority of findings have demonstrated a female advantage in odor identification ability. The female superiority is prevalent in both free identification (Cain, 1982; Doty, Applebaum, Zusho, \& Settle, 1985; Wysocki \& Gilbert, 1989; Öberg, et al., 2002), and cued identification tasks (Larsson, Nilsson, Olofsson, \& Nordin, 2004; Segal et al., 1995). However, it is worth noting that other studies have failed to find a significant influence of sex in odor identification tasks (Kobal et al., 2000; Larsson, Finkel, \& Pedersen, 2000). Some research reports that the sex effect may vary as a function of age, such that the female superiority is more pronounced in older as compared to younger individuals (Ship, Pearson, Cruise, Brant, \& Metter, 1996).

For episodic odor memory (i.e., odor recognition), studies indicate a sex difference in favor of women (Choudhury, Moberg, \& Doty, 2003; Larsson, Lövdèn \& Nilsson, 2003; Lerhner, 1993), that corroborates the well established female advantage in episodic memory for other types of sensory information (Herlitz, Nilsson, \& Bäckman, 1997; Zelinski, Gilewski, \& Schaie 1993). Possible explanations of the observed sex difference in episodic odor memory are the female superiority in verbal abilities (Larsson et al., 2003; Öberg et al., 2002), and/or a keener sense of smell (Lerhner, 1993).

Hence, the overall pattern of findings suggests that sex differences are present in most olfactory tasks.

\section{Education}

There is a large individual variation in the relationship between the degree of brain pathology and behavioral function (Katzman et al., 1989; Stern, 2006). These findings have lead researchers to suggest a theoretical construct that may account for this discrepancy, namely, a cognitive reserve (for a review see Stern, 2006). The cognitive reserve theory suggests that highly educated individuals suffering from brain pathology are more likely to use strategies to recruit other brain structures or networks than those that are normally used in cognitive tasks. Results from various ethnical communities have demonstrated that individuals who lack education or have a low education are more likely to develop dementia and AD (Katzman, 1993; Mortimer \& Graves, 1993; Ott et al., 1995; Zhang et al., 1990). Thus, two patients may have a similar degree of AD pathology but appear different in their clinical picture given their different educational background (Stern, 2006). Findings like these demonstrate that education may exert a significant impact on AD diagnosis and that education may serve as an index of the cognitive reserve. The concept of a cognitive reserve can be extended to account for individual variation in healthy individuals as well. For example, educational attainment 
has a high correlation with scores on standard tests of intelligence (Matarazzo \& Herman, 1984). Also during normal aging, the educational background may exert a greater influence on cognitive performance than chronological age itself (Ardila \& Rosselli, 1989). It is important to note that the reserve hypothesis has been classified into a cognitive and a brain model (Stern, 2009). The cognitive reserve described previously, suggests that the brain actively cope with brain damage using cognitive processes. In contrast, the brain reserve is a passive model where the reserve derives from brain size or the number of neurons inherent from birth.

A previous study based on the Betula project demonstrated that formal years of education accounted for significant proportions of the variance in both episodic and semantic memory tasks (Nyberg, Bäckman, Erngrund, Olofsson, \& Nilsson, 1996). Also, education had a strong negative correlation with age, indicating that younger adults had more formal years of education than older adults. Given that education affects cognitive performance it is of importance to also control for educational background in the analyses of aging. The influence of education on olfactory functions is sparsely investigated. Given that odor identification and semantic memory draw on similar cognitive abilities (Larsson et al., 2000), education may be a significant background variable in olfactory tasks as well. Indeed, findings suggest that years of formal education, irrespective of age, share variance with olfactory identification ability, such that high education is positively related to olfactory proficiency (Larsson et al., 2004). Thus, in age-heterogeneous population samples it is important to consider educational background when evaluating higher-order olfactory function.

\section{Health factors}

Olfactory disorders are more common in the population than is widely believed. In an adult Swedish population the overall prevalence of olfactory dysfunction was reported to be about $19 \%$ (Brämerson et al., 2004). Among these people, $13 \%$ were hyposmic, that is they had a diminished sense of smell, and $6 \%$ were anosmic, which is a total loss of smell function. It is important to note that such olfactory impairments could be a secondary effect of other disease conditions. The olfactory sense has proven to be vulnerable for a variety of diseases (Deems et al., 1991; Murphy et al., 2002). Nasal and sinus disease, diabetes, head trauma, stroke, epilepsy, nasal congestion, upper respiratory tract infection, and depression are some of the most common diseases associated with olfactory dysfunction (Deems et al., 1991; Dileo \& Amedee, 1994; Le Floch, Lièvre, Labroue, Peynegre, \& Perlemuter, 1993; Murphy et al., 2002; Weinstock, Wright, \& Smith, 1993). An olfactory impairment is also, as will be discussed in more detail below, often pre- 
sent in neurological disorders, such as Parkinson's and Alzheimer's disease (Doty, Reyes \& Gregor, 1987; Hawkes, Shephard, \& Daniel, 1997; Karpa et al., 2010; Murphy, 1999).

Taken together, in the evaluation of population-based olfactory functions, a range of demographic factors such as sex, education, and health need to be taken into consideration. 


\section{Cognition and memory: an overview}

The studies included in this thesis comprise both olfactory and other cognitive tasks. Since relationships among cognitive and olfactory functions will be discussed throughout this thesis, the section below will briefly cover a description of the different memory systems and the impact of aging on these systems.

Human memory is not a single faculty of mind, but rather composed of a variety of distinct and dissociable processes and systems (Schacter \& Tulving, 1994). Although these systems subserve each other, they operate according to different principles. Functional, structural, and lesion data support the division of different memory systems into at least five different systems: Procedural memory, the perceptual representation system (PRS), semantic memory, working memory, and episodic memory (Gabrieli, 1998; Schacter \& Tulving, 1994). Procedural memory refers to procedural and motor skills (Gupta \& Cohen, 2002). The perceptual representation system (PRS), priming, is an implicit memory that does not require explicit recollection of a specific prior episode (Schacter, 1990). Semantic memory refers to memory for factual knowledge about the world (Schacter \& Tulving, 1994). Episodic memory enables us to remember personally experienced events (Tulving, 2000). Working memory is for temporary storing and manipulation of information (Baddely, 2003). Due to its limited time capacity, working memory is often referred to as short-term memory, whereas other systems are viewed as long-term memory systems (see Figure 1). Working memory is closely related to executive function that involves shifting between tasks or mental sets, updating and monitoring of working memory representations, and inhibition of responses (Miyake et al., 2000). The memory systems can further be divided into declarative and non-declarative memory (Squire, 1992). The latter comprises procedural memory and PRS. Semantic memory, working memory, and episodic memory store information learned through awareness and are components of declarative memory. The ontogenetic and phylogenetic aspects of the memory systems are important: the latest evolved system (episodic memory) is the most sensitive to disturbances, whereas earlier developed systems (PRS, procedure memory) are more robust. 


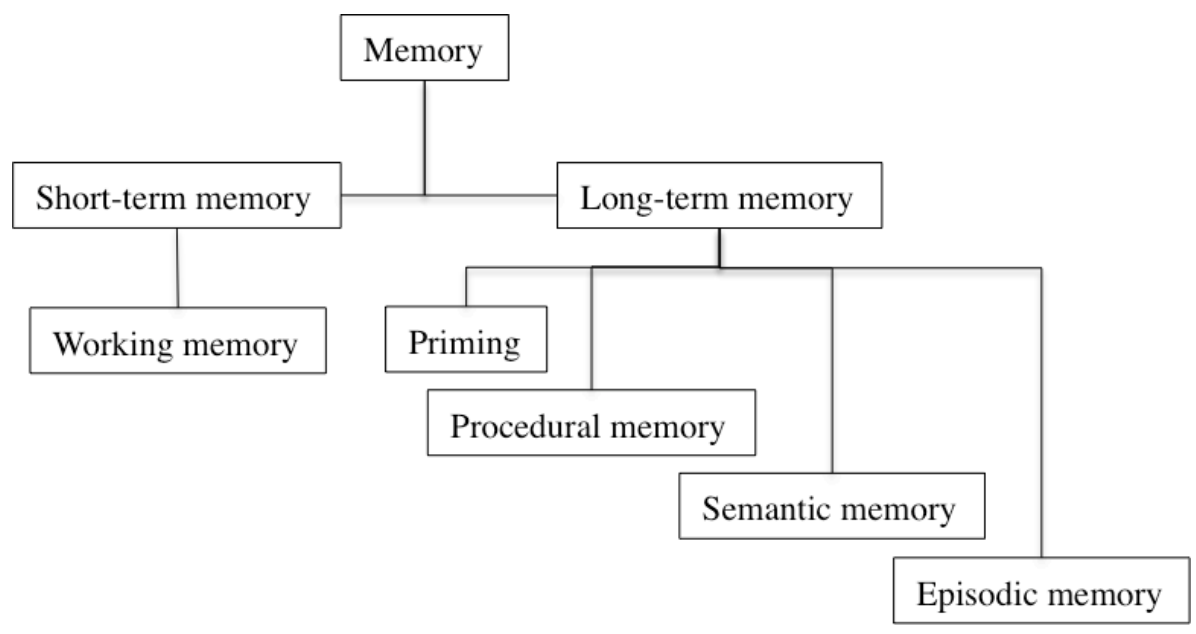

Figure 1. Taxonomy of the human memory.

\section{Cognitive aging}

It is well established that memory performance deteriorates with advancing age and differentially in various strata of elderly. However, several lines of evidence show that the effects of aging vary across different memory systems (Craik \& Jennings, 1992; Nilsson, 2003). Aging takes the greatest toll on episodic memory and more so on free recall of information than on recognition (Nyberg et al., 2003). Semantic memory is affected by aging as well, although this effect can disappear when educational level is taken into account (Nilsson et al., 1997). Age is associated with lower scores on measures of working memory functioning, although many of the age-related influences appear to be mediated by a slower speed of processing (Salthouse, 1994). The non-declarative memory systems appear to be stable across the life-span and do not seem to be affected by the aging process (Nilsson et al., 1997). 


\section{Cognitive factors in olfactory function}

The olfactory tasks included in this thesis are odor threshold (Study I), odor discrimination (Study II), and odor identification (Study I, II, and III). Below I will review these functions in more detail.

Based on available evidence, Larsson (2002) conceptualized a theoretical framework to further the understanding regarding the relationships between different olfactory functions and forms of memory (i.e., memory systems). A tentative classification scheme is provided in Table 1.

Table 1. Classification scheme: olfactory functions and their corresponding memory system (adapted from Larsson, 2002).

\begin{tabular}{ll}
\hline \hline Memory system & Olfactory function \\
\hline Procedural memory & Odor conditioning; aversions \\
Perceptual representation system & Odor priming \\
Semantic memory & Hedonics, familiarity; \\
Working memory & identification; metamemory \\
Episodic memory & Odor discrimination \\
\hline \hline
\end{tabular}

\section{Odor detection}

The most commonly used methods for determining olfactory threshold are the staircase method, the method of limits, and the method of constant stimuli. All methods have shown to yield reasonable good estimates of average threshold in an individual (Doty, Smith, Mckeown, \& Raj, 1994; Wise, Bien, \& Wysocki, 2007). In general, measurements of olfactory thresholds are thought to draw primarily on sensory processes. Few studies have investigated if threshold measurements also involve cognitive components. Func- 
tional brain imaging data and structural volumetric data support the notion of olfactory threshold detection as a primarily sensory driven task (Frasnelli et al., 2010; Savic, Gulyas, Larsson, \& Roland, 2000; Seubert, Freiherr, Frasnelli, Hummel, \& Lundström, 2012). Larsson et al. (2000) found no influence of cognitive factors in an odor detection task. However, hypothetically, the assessment of olfactory thresholds may tap discrimination abilities since the subject needs to detect the difference between a target and a blank. Indeed, there is some evidence indicating that olfactory threshold tests may draw on cognitive functions. A study by Dulay, Gesteland, Shear, Ritchey, and Frank (2008), measured the influence of cognition on different olfactory tasks with a structural equation modeling (SEM) analysis. The results showed that the odor threshold task loaded on both working memory and processing speed although to a lesser extent than the odor identification task. However, a recent developed method, the Sniff Magnitude Test (SMT), assesses olfactory function by measuring changes in inhalation in response to an unpleasant odor (Frank, Dulay, \& Gesteland, 2003; Mainland \& Sobel, 2006). Results derived from the SMT have shown to be unrelated to cognitive demands, indicating that this method primarily relies on sensory factors (Dulay et al., 2008).

\section{Odor discrimination}

Olfactory discrimination is assessed by means of quality discrimination (similar/dissimilar) or intensity discrimination (stronger/weaker). Although discrimination has been viewed as primarily a sensory task (Danthiir, Roberts, Pallier, \& Stankov, 2001), the shifting from one presented odor to another and a continuous updating with a new olfactory representation may tap executive functioning (Dulay et al., 2008; Miyake et al., 2000). At a first step, an odor must be detected, and the subject must be able to form a transient representation of the target odor and to use this information for comparison and subsequent selection of the target odor from a set of distractors. Discrimination performance will increase if the odors are presented with a higher intensity or if odor labels are provided (de Wijk \& Cain, 1994). Rabin (1988) manipulated odor discrimination ability in a series of experiments. The results revealed that experience with the specific target odor (i.e., label and profile training) prior to testing enhanced the ability to discriminate between them. Semantic memory may be engaged as an additional strategy in shifting and updating working memory by labeling the different olfactory stimuli provided.

Brain imaging data indicate that olfactory information is processed in a hierarchical manner. Savic et al. (2000) reported that discrimination by quality and odor recognition activated a wider cortical network than intensity dis- 
crimination and passive smelling. These data suggest that intensity discrimination may depend less on cognitive factors, whereas discrimination of quality is a more cognitively driven process. Moreover, it is of interest to note that patients with temporal lobe lesions typically have normal olfactory threshold values but show deficits in quality discrimination ability, which suggests that odor discrimination depend on other neural structures than threshold tasks (Zatorre \& Jones-Gotman, 1991). However, evidence from Korsakoff patients show impaired odor discrimination ability but intact odor memory, suggesting that different mechanisms underlie odor memory processing and odor discrimination ability (Herz \& Engen, 1996; Mair, Carpra, McEntee, \& Engen, 1980).

\section{Odor identification}

Both odor familiarity and odor naming (i.e., odor identification) depend on prior knowledge of an odor (i.e., semantic memory) (Finkel, Pedersen, \& Larsson, 2001; Larsson et al., 2000). In a familiarity task the subjects are usually instructed to rate the perceived familiarity (from high to low) of a given odor. Odor identification is often a more difficult task than expected and even though an odor is highly familiar it is common that people fail to generate its correct name. Also everyday odors, which are highly overlearned, may prove extremely difficult to name. The tip-of-the-nose phenomenon was introduced by Lawless and Engen (1977) and relates to a strong feeling of recognizing the odor but still being unable to produce its specific label. Current evidence suggests that the inability to correctly name an odor is not due to a poor association between the odor and its label but rather a failure to identify the odor (Jönsson, Tchekhova, Lönner, \& Olsson, 2005).

Odor identification can be assessed both by means of free identification and cued identification. In free odor identification, young adults can name about $22-57 \%$ of the presented odors (Larsson, 1997), whereas in cued identification, performance can reach ceiling-levels (Doty et al., 1994). It is not surprising that subjects perform better in cued than in free odor identification. When cues are provided, the task is more supportive in the sense that the subject only has to match the odor sensation to the appropriate label. In free identification, the subjects have to initiate a search process in order to retrieve the correct label. Four alternatives per test stimuli is a common test procedure as more response items may pose too high task demands (Nordin, Brämerson, Liden, \& Bende, 1998). The selection of response alternatives is important since cued identification performance is dependent on the similarity between the target odor and the distractors. Engen (1987) reported that for highly dissimilar odors (e.g. pizza, turpentine, and clove for the target 
grape), identification performance reached 93\%. However, if the selected distractors were highly similar to the target odor (melon, strawberry, and plum) identification dropped to about $50 \%$.

As noted above, several studies have reported an association between semantic memory and odor identification performance (Economou, 2003; Finkel et al., 2001; Larsson et al., 2000). Also, by employing SEM techniques, Dulay et al., (2008) reported that non-olfactory cognitive abilities such as verbal retrieval, working memory, and cognitive processing speed contributed significantly to odor identification performance. In a principal component factor analysis, Dantiir et al. (2001) showed that odor identification loaded on crystallized intelligence, a factor clearly defined by general knowledge and vocabulary. In line with this finding, Larsson et al. (2004) reported that cognitive speed and vocabulary ability predicted odor identification performance.

Taken together, current evidence shows that odor identification performance share variance with a number of different cognitive functions, such as verbal knowledge, working memory, and processing speed.

\section{Odor recognition}

As noted above, episodic memory is assessed by means of recall and recognition tasks. For olfactory information, episodic memory is measured using recognition paradigms. In an odor recognition task the participant is first presented with a set of odors and then instructed to discriminate previous encountered odors from new ones (distractors). Of course, in order to successfully encode the odor, the subject needs to be able to perceive the odor sensation and to discriminate between the ones presented. In this respect, odor recognition may be regarded as a higher-order odor processing task, reflecting both cognitive and sensory processes (Savic et al., 2000).

Earlier evidence suggested that odors are encoded in a holistic way with no influence of semantic factors and that odor memory is resistant to interference and forgetting (Engen, 1987; Engen \& Ross, 1973). However, this view has been challenged in more recent work. Clearly, odor recognition ability depends on semantic knowledge, since factors such as perceived familiarity and identifiability are positively related to performance in odor recognition (Larsson \& Bäckman, 1993; Larsson \& Bäckman, 1997; Murphy, Cain, Gilmore, \& Skinner, 1991; Rabin \& Cain, 1984). Also, evidence indicates that episodic odor memory is very prone to forgetting and that odor recognition decline is more pronounced over a 6 months interval as compared to other sensory stimuli (Larsson \& Bäckman, 1993; Murphy et al., 1991). 


\section{Relationships among olfactory tasks}

There are moderate to strong relationships among tests assessing different aspects of olfactory function. For example, tests of odor identification typically have high positive correlations with odor threshold tasks (Cain \& Rabin, 1989; Hummel, Sekinger, Wolf, Pauli, \& Kobal, 1997). Discrimination is positively correlated with both free and cued identification ability (de Wijk \& Cain, 1994). Lehrner, Gluck, and Laska (1999) investigated olfactory functions across the lifespan and reported that detection was correlated with odor memory, although only marginally in old age. Also, a vast majority of findings have documented strong relationships between odor identification and odor recognition, such that a successfully identified odor is easier to recognize at a later occasion (Larsson \& Bäckman, 1993; Larsson \& Bäckman, 1997; Murphy et al., 1991; Rabin \& Cain, 1984). In a principal component analysis including olfactory tests of threshold, discrimination, recognition, and identification, Doty et al. (1994) reported that olfactory tests share a common source of variance suggesting that olfactory function is multidimensional. For example, the act of detecting an odor also requires the ability to remember the odorant and to discriminate it from a blank. Also, logically, if a subject has a poor ability to detect an odor this would implicate that the subject would be impaired in higher-order cognitive tasks since no odor sensation is available for encoding. Further, olfactory identification is dependent on both the bottom-up process of sensory functioning and the top-down process of cognitive abilities (Richardsson \& Zucco, 1989). In a series of experiments, Cain and Potts (1996) reported that misidentification may depend on a misperception. The generation of an incorrect odor may originate from a failure in quality discrimination. For example, if a subject mistake orange for lemon it could be due to that the subject perceived orange, and not lemon, at encoding.

Functional brain imaging data suggest that olfactory functions are mediated by both parallel and hierarchical processing, such that odor identification, odor recognition memory, and odor quality discrimination recruit more and different areas than less complex olfactory tasks, such as odor intensity discrimination and passive smelling (Savic et al., 2000). In recent work, Seubert et al. (2012) reported that different brain areas predict distinct aspects of olfactory performance. Thus, different olfactory tasks vary in the extent to which they recruit different brain structures and networks.

To summarize, cognitive factors play a significant role in higher-order olfactory tasks and different olfactory tasks share a significant portion of variance, although some evidence are mixed. Given that demographic factors, such as aging, takes a toll on both cognitive and olfactory processes some of 
the inconsistent findings in olfactory function may be understood by considering potential age-related influences on cognitive functioning. 


\section{Olfaction in normal aging, MCI, and dementia}

Aging takes a toll on olfactory functions. Murphy et al. (2002) reported that the presence of an olfactory dysfunction is $25 \%$ in the general American population of elderly. In addition, the prevalence increased with increasing age. Surprisingly, the lack of awareness of olfactory impairments is very high, as only about $20 \%$ of the subjects with olfactory impairment report that they had an abnormal smell function (Murphy et al., 2002). The proportion of elderly in the population is growing fast. In the European population the prevalence of dementia increases continuously with age and AD accounts for most of the dementia cases (about 60 to 70\%) (Fratiglioni et al., 2000). Below, the close relationship between age and olfactory ability will be presented. Given the high risk of AD in older age and the presence of olfactory dysfunction in $\mathrm{AD}$, this potential association will also be discussed.

\section{Olfactory function in normal aging}

Aging is accompanied by a gradual loss of olfactory ability. On a biological basis, the age-related changes in the smell functions can be explained by a deterioration of olfactory receptor neurons (ORN) (Rawson, Gomez, Cowart, \& Restrepo, 1998). The ORNs have been found to be regenerated at a slower pace in the olfactory epithelium in old compared to young adults and the selectivity of the ORNs may vary as a function of age (Loo, Youngentob, Kent, \& Schwob, 1996; Rawson et al., 1998). In addition, the surface area of the olfactory epithelium becomes gradually smaller with increasing age. The processing speed of olfactory information decreases in normal aging for both the sensory and cognitive components in event-related potentials (Hummel, Barz, Pauli, \& Kobal, 1998; Murphy, et al., 2000). Further evidence from olfactory neuroimaging studies show an age-related decrease in brain activity in olfactory structures (Cerf-Ducastel \& Murphy, 2009; Wang, Eslinger, Smith, \& Yang, 2005).

All olfactory functions are negatively affected by age. Odor thresholds increase with aging (Kaneda et al., 2000; Larsson et al., 2000; Murphy, Nordin, de Wijk, Cain, \& Polich, 1994; Stevens \& Cain, 1987), although a loss in odor sensitivity may not always a feature in aging. For example, Nordin, 
Almkvist, and Berglund (2012) demonstrated that a subgroup of older subjects without any medical, health or cognitive deficits (i.e. successfully aged) known to affect olfactory abilities performed at the same level as young adults, suggesting that factors secondary to aging are responsible for the odor detection deficits in older individuals. Other evidence indicates that the size of the age effect in odor sensitivity varies as a function of the type of odor (Wysocki \& Gilbert, 1989).

Similarly, young outperform old adults in odor quality discrimination (Hummel et al., 1998; Kaneda et al., 2000; Schemper, Voss, \& Cain, 1981). In a study by de Wijk and Cain (1994) age was negatively correlated with both odor discrimination and odor identification performance. Interestingly, controlling for odor identification indicate that the association between aging and discrimination was not driven by age-related odor identification impairments.

Likewise, both odor identification and odor recognition are negatively affected by aging (Larsson, 1997; Larsson \& Bäckman, 1993; Larsson et al., 2004; Lehrner et al., 1999; Murphy et al., 1991; Ship \& Weiffenbach, 1993). A vast majority of findings report of age-related impairments in odor identification ability (Doty et al., 1984; Dulay et al., 2008; Larsson et al., 2000). Doty et al. (1984) documented that odor identification reached a plateau in between 20 to 40 years of age after which a gradual loss of olfactory abilities commenced. In addition, de Wijk and Cain (1994b) demonstrated that odor identification ability over the life-span follows an inverted U-shape, such that young adults outperform children and elderly. It is of interest to note that the age-related impairment is greater with increasing task demands, thus, the age effect is larger in free than in cued identification tasks (de Wijk \& Cain 1994; Schemper et al.,1981). Also, age-related deficits in odor identification may vary with the hedonic qualities of odors (Konstantinidis, Hummel, \& Larsson, 2006; Wysocki \& Gilmore, 1989). Konstantinidis et al. (2006) found a strong age effect for pleasant odors, whereas identification of unpleasant odors was independent of age.

Yet, few studies have investigated the effects of age on odor identification using a longitudinal study design. Ship et al. (1996) confirmed and extended the cross-sectional findings on age-related impairments in odor function by studying odor identification over a three-year period. In their work, odor identification decreased as a function of age, and the deterioration was faster with increasing age. Notably, a sex $\times$ age interaction was found such that the olfactory decrement started in the middle-age for men and around 75 years of age among women. However, other work did not find an interaction between sex and age in either odor identification or odor detection (Larsson et al., 2000). 
Lehrner et al., (1999) reported that elderly subjects exhibited a detection impairment and that the detection thresholds were correlated with episodic odor memory, suggesting that a primary sensory impairment may be responsible for the odor recognition impairment observed in old age. Also, older subjects were impaired in remembering odors that had been identified correctly in an earlier task. However, odors that were not correctly identified obtained equal recognition performance across age groups, suggesting that there is a recollection-based odor memory system that declines with age and a familiarity-based system that shows age invariance. In agreement with this, Murphy et al. (1991) found that an age-related effect in short-term odor recognition was true only for odors with a low familiarity. Since semantic odor knowledge is known to influence odor recognition (Larsson, 1997), age-related deficits in odor recognition may share variance with age-related impairments in odor identification. Larsson and Bäckman (1993, 1997) found that controlling for odor naming eliminated the age-related impairments in odor recognition, suggesting that decrements in cognitive olfaction function (i.e., odor identification) rather than sensory deficits underlie the age deficits in higher-order olfactory functions. Taken together, these data suggest that identifiability and familiarity play significant roles for agerelated odor recognition deficits.

One important question concerns to what extent age-related decrements in higher olfactory functions result from cognitive deficits and/or a sensory loss? Murphy et al. (1991) demonstrated that odor recognition performance is significantly impaired in the elderly and that this age deficit in part was related to deficits in threshold performance. Further, Larsson et al. (2004) reported that demographic and cognitive variables could not fully explain the age-related variance in odor identification suggesting that basic sensory abilities also play a fundamental role. However, it is clear that sensory deficits alone cannot explain the age-related impairment in odor recognition memory and odor identification (Larsson \& Bäckman, 1993; Larsson \& Bäckman, 1997; Murphy et al., 1991). Given that olfactory tests share a common source of variance (Doty et al., 1994), and that cognitive abilities are recruited in olfactory tasks (Larsson, 1997; Richardsson \& Zucco, 1989), performance across olfactory tasks may rely on a shared factor loading. For other sensory stimuli (hearing and vision) Baltes and Lindenberger (1997) reported a strong connection between sensory and cognitive functions that varies across the lifespan, such that the proportion of shared variance is amplified in older ages. In their study they argue that the common cause hypothesis accounts for the age-related connection between sensory and intellectual functioning. The common cause hypothesis stipulates that correlations between sensory and cognitive functioning increase due to age-related physiological loss in the brain (Baltes \& Lindenberger, 1997). In a similar 
vein, Salthouse, Hambrick, and McGuthry (1998) showed that cognitive as well as and noncognitive variables share age-related variance. In addition, the proportion of shared variance was substantially reduced after controlling for the influence of age. In a seminal study, Dulay and Murphy (2002) demonstrated that the common cause hypothesis was true for cognitive functioning and olfactory acuity as well. Olfactory acuity (as indexed by a threshold task and an alcohol sniff test) and cognition (as indexed by a composite of various cognitive tests) was entered in a SEM analysis. The results indicated that the "cognition" latent factor and the "olfaction" latent factor were related to a second-order common factor, which in turn was affected by chronological age, such that olfactory and cognitive functions were relatively unrelated in young age but converged in old age. Possible explanations for these observations are that age-related degeneration and anatomical losses in the CNS affect both olfactory and cognitive processes. Altogether, the authors concluded that olfactory performance may represent a valid index for the neural integrity of the aging brain (Dulay \& Murphy, 2002).

It is worth noting that research suggest that impaired odor function precedes age-related cognitive deficits. In longitudinal studies of elderly cohorts, odor identification impairments were associated with lower levels of global cognition (Wilson, Robert, Arnold, Tang, \& Bennett, 2006; Olofsson et al., 2009). Also, Finkel,Reynolds, Larsson, Gatz, and Pedersen (2011) reported that high odor identification performance predicted better performance on cognitive tasks, such as verbal ability, processing speed, and memory, although no predicted evidence of odor identification on longitudinal cognitive change was observed.

In conclusion, aging is accompanied by olfactory dysfunction, which is present in sensory as well as cognitively driven olfactory tasks.

\section{Olfactory function in MCI and dementia}

The cause of $\mathrm{AD}$ remains unclear, although much research has focused on the pathology behind the disease. $\mathrm{AD}$ is a degenerative disease characterized by so-called senile plaques and tangles with a predominant clustering in limbic and temporal brain regions (Braak \& Braak, 1991). These plaques are believed to be the result of an overproduction of beta-amyloid in the brain (Gazzaniga, Ivry, \& Mangun, 2002). The olfactory bulb is one of first the regions where Alzheimer-type pathology (senile plaques, tangles, and betaamyloid) is manifested in the brain (Christen-Zaech et al., 2003; Kovacs, 2004). Although the clinical symptoms of AD are well established, it is clear that AD patients represent a heterogeneous group. Patients exhibit various 
cognitive impairments, and these deteriorate at different rates during the disease progression (Cummings, 2000; Teri, Hughes, \& Larson, 1990). Also, there is a discrepancy in terms of clinical symptoms and the degree of pathological damage (Braak \& Braak, 1991; Katzman et al., 1989; Riley, Snowdon, \& Markesbery, 2002).

There are numerous studies showing that neurodegenerative diseases such as AD are linked to olfactory impairments (for review see Mesholam, Moberg, Mahr, \& Doty, 1998). In 1995, Morgan, Nordin, and Murphy reported that AD patients were more impaired in odor identification than in picture identification tasks. These authors suggested that assessment of odor identification in the evaluation of an $\mathrm{AD}$ diagnosis could be fruitful. In addition to these observations, several studies have found impaired odor identification abilities in subjects at risk for AD (Devanand et al., 2008; Koss, Weiffenbach, Haxby, \& Friedland, 1988; Larsson et al., 1999; Morgan et al., 1995). Also, results suggest that a low olfactory identification performance can predict the subsequent development of MCI in older persons without cognitive impairment at baseline (Wilson et al., 2007). Mild cognitive impairment (MCI) is a common diagnosis that is difficult to classify. It is frequently used to describe non-demented people with a type of memory loss that is not considered to be associated with the normal aging process. Studies show that 10 - $15 \%$ of the people with MCI progress to AD within a year (Petersen et al., 1999). As MCI can be considered a transitional stage between normal aging and AD it is important to study MCI patients as current evidence suggest that the odor impairments are present in people at high risk of developing AD. However, it should be noted that the MCI concept has been widely criticized for being too broad. In 2011, a new concept was suggested, "MCI due to AD", that combines biomarkers such as beta-amyloid and neuronal injury with a decline in cognition and some evidence of impairment in one or more cognitive domains, typically including memory (Albert et al., 2011). Schubert et al., (2008) found that odor identification deficits were associated with a significant cognitive impairment at a five-year later follow-up in an older population. Further, Devanand et al. (2000) reported that olfaction scores were lower in patients with MCI as compared to healthy subjects. Also, the olfactory identification deficits together with lack of awareness of the olfactory deficits in MCI patients predicted conversion to $\mathrm{AD}$ in a three-year follow-up study where patients were followed at six-month intervals. Djordjevic, Jones-Gotman, De Sousa, and Chertkow (2008) replicated and extended these findings by demonstrating that MCI patients show deficits in three olfactory domains: olfactory thresholds, discrimination, and identification. Regarding the impact of olfactory sensitivity (i.e., thresholds) in AD progression evidence is mixed. Some studies suggest that an olfactory threshold impairment precedes the AD diagnosis (Bacon, Bondi, Salmon, \& Murphy, 1998; Djordjevic et al., 2008), and that increased olfactory thresh- 
olds in patients with AD reflect the effects of the disease process (Morgan et al., 1995; Murphy, Gilmore, Seery, Salmon, \& Lasker, 1990; Nordin, Almkvist, Berglund, \& Wahlund, 1997). Others report of no odor threshold impairment in the preclinical stage, suggesting that the selective odor identification deficit reflects that the olfactory impairment in AD is central rather than peripherally driven (Koss et al., 1988; Larsson et al., 1999; Serby, Larson, \& Kalkstein, 1991). In line with these findings, longitudinal studies show that olfactory impairments are significantly related to MMSE (MiniMental State Examination) performance and appear to precede the impairment and memory loss in preclinical AD (Graves et al., 1999).

In sum, available evidence indicates that higher-order olfactory deficits may be present early in an $\mathrm{AD}$ diagnosis. 


\section{Behavioral genetics}

Twin and adoption studies indicate that genes account for about half of the variance in cognitive abilities (IQ), although the genetic impact on specific cognitive abilities is much lower (Pedersen, Plomin, Nesselroade, \& McClearn, 1992; Deary, Spinath, \& Bates, 2006; Bouchard \& McGue, 2003). Evidence suggests that gene expression is distributed widely throughout the CNS rather than being localized in specific brain regions affecting specific cognitive functions (Kovas \& Plomin, 2006). Multivariate genetic analyses predict that genes that influence a specific cognitive trait also will be associated with other similar cognitive abilities (Deary et al., 2006). Interestingly, the relative importance of genetic influence may vary with age (Bouchard \& McGue, 2003). From infancy to middle age, the impact of genetic factors increase while shared environmental influences decrease. For the oldest cohorts, some studies have reported the opposite: that heritability in general cognitive abilities decreases (Finkel, Pedersen, McGue, \& McClearn, 1995; Finkel, Pedersen, Plomin, \& McClearn, 1998), although the available findings represent a mixed pattern of findings (Pedersen et al., 1992). A recent study by Deary et al. (2012) suggests that the same genes are associated with a cognitive trait throughout life, with possibly some genetic variation for cognitive change. However, although genes may account for a small proportion of age-related cognitive decline there may be a gene $\times$ environment interaction that makes a person more or less susceptible to environmental effects on cognitive traits.

Available evidence suggests that the role played by specific genes for a certain behavior may vary over the lifespan. For example, the ApoE gene has been found to affect cognitive proficiency in old age but has little or no impact in younger ages (for review see Small, Rosnick, Fratiglioni, \& Bäckman, 2004). In addition, specific genes can be expressed differently in different developmental stages (Lu, Pang, \& Woo, 2005), such that a genotype may exert an unexpected effect on cognition in older age compared to its effect in younger age (Erickson et al., 2008). 


\section{Genes and olfaction}

Neuroscientists Linda Buck and Richard Axel demystified the olfactory sense in 1991 by discovering a family of approximately 1000 genes that encode the olfactory receptors in rodents. They found that each olfactory receptor cell, residing in the olfactory epithelium, is highly specialized for a small number of odors (Buck \& Axel, 1991). Their groundbreaking research findings, for which they later received the Nobel Prize, opened the door to the genetic analysis of the mechanisms of olfaction. The human olfactory system contains several millions of olfactory sensory neurons, each expressing one of approximately 350 olfactory functional receptor genes where each receptor responds to several odorants. Although humans have about 1000 receptor genes, the majority has been mutated into non-coding pseudogenes (Keller \& Vosshall, 2004). Keller, Zhuang, Chi, Vosshall, and Matsunami (2007) have demonstrated that the different genetic makeup in individuals contributes to variability in human odor perception. Their study, which was the first such gene-behavior link in the domain of olfaction, reported that a genotypic variation in OR7D4 accounted for androstenone sensitivity. A twin study by Finkel et al. (2001) demonstrated a heritability for odor identification and perceived intensity, however, there was no genetic variance for odor identification that was independent of genetic variance for the cognitive measures. Even though earlier studies suggest that there is a large genetic component involved in olfactory processing, few genes contributing to individual differences in olfactory proficiency have been identified (Finkel et al., 2001; Segal et al., 2005).

\section{Apolipoprotein E (ApoE)}

The Apolipoprotein E (ApoE) gene is located on chromosome 19 involved in transport of cholesterol and of lipids in plasma and in other body fluids (Laws, Hone, Gandy, \& Martins, 2003). The ApoE gene is present in cells of several organs which synthesize ApoE, including the liver and the brain. The ApoE gene carries three primary alleles: $\varepsilon 2, \varepsilon 3, \varepsilon 4$, forming six possible genotypes: $\varepsilon 2 / \varepsilon 2, \varepsilon 2 / \varepsilon 3, \varepsilon 2 / \varepsilon 4, \varepsilon 3 / \varepsilon 3, \varepsilon 3 / \varepsilon 4$, and $\varepsilon 4 / \varepsilon 4$ for a specific individual. The distribution of the three alleles varies in different populations and in a Scandinavian population the frequencies of the different alleles has been estimated to $4.1 \%, 73.3 \%$, and $22.7 \%$ for ApoE $\varepsilon 2$, ApoE $\varepsilon 3$ and ApoE $\varepsilon 4$ respectively (Corbo \& Scacchi, 1999; Ehnholm, Lukka, Kuusi, Nikkilä, \& Uttermann, 1986). The ApoE gene has long been recognized as a candidate gene for cardiovascular diseases (Gylling \& Miettinen, 1992; Kamboh, Weiss, \& Ferrell, 1991). However, in recent years it has also been associated with neurodegenerative diseases such as late-onset AD (Bertram, McQueen, Mullin, Blacker, \& Tanzi, 2007; Coon et al., 2007; Corder et al., 1993; Rebeck, Reiter, Strickland, \& Hyman, 1993). 


\section{ApoE and Alzheimer's Disease}

There are a number of studies investigating genes that may play a role in the development and progression of AD. The ApoE gene is one of the few candidate genes that show a consistency and reliability across studies (Bertram, 2004). Subjects carrying at least one copy of the $\varepsilon 4$ allele have a significantly increased risk of developing common familial and sporadic late-onset AD (Coon et al., 2007; Raber, Huang, \& Ashford, 2004; Roses, 1998). Also, a dose effect of the ApoE $\varepsilon 4$ allele has been documented, such that homozygous carriers (genotype $\varepsilon 4 / \varepsilon 4$ ) are associated with lower age at onset and a faster rate of cognitive decline in the progression of AD (Breitner et al., 1999; Craft et al., 1998).

As noted above, $\mathrm{AD}$ is a degenerative disease characterized by so-called senile plaques and tangles that predominantly cluster in limbic and temporal brain regions. These plaques are believed to be the result of an overproduction of beta-amyloid in the brain (Gazzaniga, Ivry, Mangun, 2002). Some evidence suggests that the ApoE gene appears to contribute directly to the pathogenesis of $\mathrm{AD}$ by promoting amyloid plaques (and possibly neurofibrillary tangles) in the brain (Kamboh, 1991; Raber et al., 2004; Sunderland et al., 2004). Although much research has been aimed at finding the causal link to $\mathrm{AD}$, it is still uncertain whether the pathological manifestations mentioned above is the basis behind the disease or just an epiphenomenon, i.e. a secondary symptom. It is important to note that not all ApoE $\varepsilon 4$ allele carriers develop $\mathrm{AD}$ and that individuals who lack the ApoE $\varepsilon 4$ allele may also develop the disease.

\section{ApoE and cognitive aging}

Compared to the BDNF val66met polymorphism, the literature regarding ApoE as a candidate gene accounting for some of the cognitive variation in the population is very consistent. Several studies have reported the ApoE gene as an important predictor of cognitive aging (Anstey \& Christensen, 2000; Blair et al., 2005; Bretsky, Guralnik, Launer, Albert, \& Seeman, 2003; Caselli et al., 2009; Finkel et al., 2011; Nilsson et al., 2006), although other studies have failed to find such an association (Bunce, Fratiglioni, Small, Winblad, \& Bäckman, 2004; Small et al., 2000). Since degenerative diseases are characterized by a gradual onset of symptoms it is difficult to determine the time course of the disease. Thus, it is difficult to dissociate the effects of ApoE $\varepsilon 4$ allele on the normal aging process from preclinical dementia stages (Nilsson et al., 2006). 


\section{ApoE and olfaction}

Several lines of research indicate a strong link between the ApoE gene and olfactory functions with or without the presence of dementia. The ApoE gene, which is expressed in the olfactory bulb and the olfactory epithelium, is associated with the continuous degeneration and regeneration processes that occur in the olfactory nerve (Nathan, Nannapaneni, Gairhe, Nwosu, \& Struble, 2007; Struble, Short, Ghobrial, \& Nathan, 1999). Also, severity of tau pathology in the olfactory bulb of AD correlates with the ApoE $\varepsilon 4$ genotype (Tsuboi et al., 2003). An early study by Murphy, Bacon, Bondi, and Salmon (1998) reported a marked odor identification deficit in nondemented old ApoE $\varepsilon 4$ allele carriers compared to non- $\varepsilon 4$ carriers. Other evidence shows that in individuals with MCI, those with the ApoE $\varepsilon 4$ allele demonstrate poorer thresholds than those without the $\varepsilon 4$ allele (Bacon et al., 1998). A longitudinal study further demonstrated that elderly people carrying the $\varepsilon 4$ allele had a significant decline over four years in odor identification but not in odor threshold, picture identification or Dementia Rating Scores (Calhoun-Haney \& Murphy, 2005). However, some studies report no association between the ApoE gene and olfactory performance (Devanand, et al., 2010; Swan \& Carmelli, 2002). Although Handley, Morrison, Miles, and Bayer (2006) did not find an independent influence of ApoE status on odor identification, there was a significant interaction between family history of $\mathrm{AD}$ and ApoE such that AD sibling $\varepsilon 4$ carriers showed the largest olfactory deficits. Also, there is recent support for the impact of ApoE and olfaction on cognitive function, longitudinal findings indicate that $\mathrm{ApoE}$ and low odor identification have unique roles in predicting cognitive performance on three cognitive domains after the age of 65: verbal ability, spatial ability, and cognitive speed (Finkel et al., 2011). In addition, the ApoE gene in combination with poor odor identification performance can serve as a marker for prospective global cognitive decline measured by the MMSE (Graves et al., 1999; Olofsson et al., 2009).

\section{Brain-derived neurotrophic factor (BDNF)}

The brain-derived neurotrophic factor (BDNF) is a growth factor highly expressed in the CNS and known to support survival, transmission, and synaptic plasticity in the cortex (Poo, 2001). The gene has multiple isoforms and the most studied single nucleotide polymorpism (SNP) of the BDNF is the val66met variant. The BDNF val66met polymorphism is located at nucleotide 196 (G/A) and produces an amino acid substitution, valine for methionine. Thus, the BDNF val66met carries two alleles, the val allele and the met allele, with a frequency of $3.4 \%$ for met $/ \mathrm{met}, 32.4 \%$ for $\mathrm{val} / \mathrm{met}$, and $64.2 \%$ for val/val respectively in a Caucasian population, however, the genotype frequencies varies across ethnical groups (Pivac et al., 2009). In a semi- 
nal study published in 2003, Egan et al. reported that secretion of BDNF is impaired by the met allele and suggested a role for the BDNF val66met in hippocampal function and episodic memory in humans. Their results made the BDNF val66met a common putative candidate gene for the study of individual variation in cognitive processes.

\section{BDNF and cognition}

Several association studies have demonstrated a role of the BDNF val66met polymorphism on human cognitive function. Hariri et al. (2003) demonstrated that subjects with at least one met allele made more recognition errors in a declarative memory task. Also, this group showed a reduced hippocampal engagement during encoding and retrieval as indicated by fMRI. In addition, $\mathrm{val} / \mathrm{val}$ carriers have been reported to have smaller hippocampal volume than $\mathrm{val} / \mathrm{met}$ heterozygotes (Bueller et al., 2006; Pezawas et al., 2004). Some studies have reported that the met allele is a risk factor for cognitive impairment in aging (Miyajima et al., 2008; Nagel et al., 2008; Raz, Rodrigue, Kennedy, \& Land, 2009), whereas other work report of opposite findings where the met allele may protect against cognitive decline (Erickson et al., 2008; Harris et al., 2005). Hence, the overall pattern of findings regarding the BDNF val66met as a candidate gene for cognition presents a complex and conflicting pattern of results. A recent meta-analysis did not establish significant associations for the genotype and any of the included phenotypes, such as general cognitive ability, memory, executive functions, visual processing skills or verbal fluency (Mandelman \& Grigorenko, 2012). However, this meta-analysis did not take age or sex into account to stratify for any effects on the association between the BDNF val66met polymorphism and cognition.

\section{BDNF and olfaction}

There is some evidence indicating that BDNF might be relevant for olfactory processing although little research has focused on this potential association. The BDNF gene is of interest to explore with regard to olfactory function since the BDNF has been found to regulate the proliferation and survival of ORNs in vivo (Simpson et al., 2002). Also, the generation and/or survival of new neurons in the adult olfactory bulb can be increased substantially by intraventricular administration of BDNF (Zigova, Pencea, Wiegand, \& Luskin, 1998). The expression of BDNF is high in regions pertaining to the sense of smell, such as the olfactory bulb, although the level of expression may decrease with increasing age (Katoh-Semba, Semba, Takeuchi, \& Kato, 1998). Bath et al. (2008) identified the BDNF val66met variant as a critical factor in the disruption of olfactory bulb neurogenesis in adult BDNF and tyrosine receptor kinase $(\mathrm{TkrB})$ knockout mice, linking the polymorphism to 
olfactory functioning in animals. Their observations indicate that an absence of BDNF and its receptor TkrB results in olfactory impairment (Bath et al., 2008). Also, given that the BDNF val66met polymorphism is related to hippocampal engagement in episodic memory tasks (Hariri et al, 2003), and that successful odor identification performance depend on hippocampal regions (Kjelvik, Evensmoen, Brezova, \& Håberg, 2012), BDNF is an interesting candidate gene to investigate regarding olfactory ability as well. To date, no research has focused on the val66met polymorphism and explored its potential effect on olfactory processing in humans. 


\section{General aims of the thesis}

Based on the available evidence reviewed above, the overall aim of this thesis was to investigate the influence of demographic, health, cognitive, and genetic factors on olfactory ability. Study II and III were carried out in the realm of a longitudinal population-based prospective study - The Betula project. More specifically, the objectives can be summarized as follows:

1. To what extent do age and sex influence olfactory function? (Study I, II, III)

2. What is the relative impact of cognitive factors, such as episodic and semantic memory, and executive functions on different olfactory tasks - i.e., odor threshold, odor discrimination, and odor identification? (Study I)

3. Does ApoE status have any unique influence on olfactory ability after controlling for demographic, health, and cognitive factors and current and pre-clinical dementia in a population-based sample? (Study II)

4. Is the BDNF val66met polymorphism associated with age-related decline in olfactory function in a sample of community-dwelling adults? (Study III) 


\section{Methods}

\section{The Betula Prospective Cohort Study}

The data from Study II and Study III in the present thesis derives from the Betula study. Betula is a large ongoing population-based longitudinal project focusing on memory, health, and aging. The main objectives of the project are to study how cognitive functions change during adult life and old age, to identify risk factors for dementia and to identify early preclinical signs of dementia. The Betula data is sampled randomly from the population of Umeå, a city located in the north of Sweden with 110,000 habitants (Nilsson et al., 1997, 2004). Participants are selected from the population registry of Umeå and contacted by mail. Inclusion criteria for participating in the study are: no severe visual or auditory handicap, no dementia, no mental retardation, and having Swedish as a first language. The participants gave their informed consent and the Betula Project obtained approval from the regional board of the ethics committee in Umeå, Sweden. In Betula, extensive psychological testing and health assessment is conducted every five years and to date, five waves covering 20 years have been accomplished (1988-1990, 1993-1995, 1998-2000, 2003-2005, and 2008-2010), and a sixth wave of measurement is planned in September 2013. The Betula project has a narrow age cohort design, that is, each sample was stratified according to ten narrow age cohorts (see Table 2). The youngest cohort was 35 years, the next 40 years, etc. up to the oldest cohort aged 100 years. In total, the test occasion included approximately 1000 subjects with the goal to recruit 100 participants in each age cohort.

\section{Study sample}

The odor identification test was added to the test battery at the third test occasion (T3), between the years 1998 to 2000 and five years later the subjects were retested using the same procedure. Olfactory assessments were not included in the test battery for the subjects in S2 and this sample was not tested at $\mathrm{T} 4$, therefore this sample was excluded from the current analyses. As shown in Table 2, Study II uses data from S1 and S3 at T3, but also includes dementia information obtained at T4. In Study III, both baseline and follow-up olfactory data were analyzed, hence, $\mathrm{S} 1$ and S3 are included at T3 and five years later, at $\mathrm{T} 4$. 
Table 2. The Betula design. The red line represents inclusion of the Scandinavian Odor Identification Test (SOIT) in the Betula test battery. Bolded text indicates data used in Study II and III.

\section{Time (years) Samples (age range)}

\begin{tabular}{|c|c|c|c|c|c|c|}
\hline T1 (1988-1990) & $\begin{array}{c}\mathrm{S} 1 \\
(35-80)\end{array}$ & & & & & \\
\hline T2 (1993-1995) & $\begin{array}{c}\text { S1 } \\
(40-85)\end{array}$ & $\begin{array}{c}\text { S2 } \\
(40-85)\end{array}$ & $\begin{array}{c}\text { S3 } \\
(35-80)\end{array}$ & & & \\
\hline T3 (1998-2000) & $\begin{array}{c}\text { S1 } \\
(45-90)\end{array}$ & $\begin{array}{c}\text { S2 } \\
(45-90)\end{array}$ & $\begin{array}{c}\text { S3 } \\
(40-85)\end{array}$ & $\begin{array}{c}\mathrm{S} 4 \\
(35-90)\end{array}$ & & \\
\hline T4 (2003-2005) & $\begin{array}{c}\text { S1 } \\
(50-95)\end{array}$ & & $\begin{array}{c}\mathrm{S3} \\
(\mathbf{4 5 - 9 0 )}\end{array}$ & & $\begin{array}{c}\text { S5 } \\
(35-95)\end{array}$ & \\
\hline T5 (2008-2010) & $\begin{array}{c}\text { S1 } \\
(55-100)\end{array}$ & & $\begin{array}{c}\text { S3 } \\
(55-95)\end{array}$ & & & $\begin{array}{c}\text { S6 } \\
(35-95)\end{array}$ \\
\hline
\end{tabular}

\section{Assessment of olfactory function}

In my thesis I have worked with different olfactory tests assessing odor threshold, odor discrimination, and odor identification. There are a number of different and validated odor tests developed for experimental and clinical settings. Below, I provide descriptions of the different olfactory functions and how they are measured.

\section{The 'Sniffin' Sticks'}

\section{Odor threshold}

An odor threshold test is used to assess the absolute sensitivity at the perceptual level, although one cannot rule out than cognitive functions also may be recruited at assessment. There are numerous ways to test the lowest concentration of an odor a subject is able to detect. The staircase method begins with detection of the lowest intensity (i.e., concentration) stimulus and the intensity is then increased one step at a time until detection. If the subject 
errs the staircase reverses and the intensity decreases until the subject discriminates out the odor from the blank. The Sniffin' Sticks threshold test uses a triple-forced-choice paradigm where one pen contains diluted phenylethyl alcohol with 16 different concentrations and the other two solvent (blank). Using the staircase method the subject has to discriminate the pen containing the odor, phenylethyl alcohol, from the others in two successive trials in order to trigger a reversal of the staircase. The mean of the last four staircase reversal points of a total of seven reversals was used as the threshold estimate (Hummel et al., 1997). In this context, it is noteworthy that research shows a large variability of thresholds across subjects, compounds and tests (Stevens, Cain \& Burke, 1988).

\section{Odor discrimination}

The Sniffin' Sticks test battery assesses odor discrimination by means of triplets of odorants (Hummel et al., 1997). The subject is presented with three odors, where two pens contain the same odor and the third a different one. The task is to pick out the odor that smells different. Criteria for the selection of odorants are based on: (i) odorants in a triplet should be similar with regard to intensity and, preferably, to their hedonic tone; (ii) correct discrimination of individual odorants should be $>75 \%$.
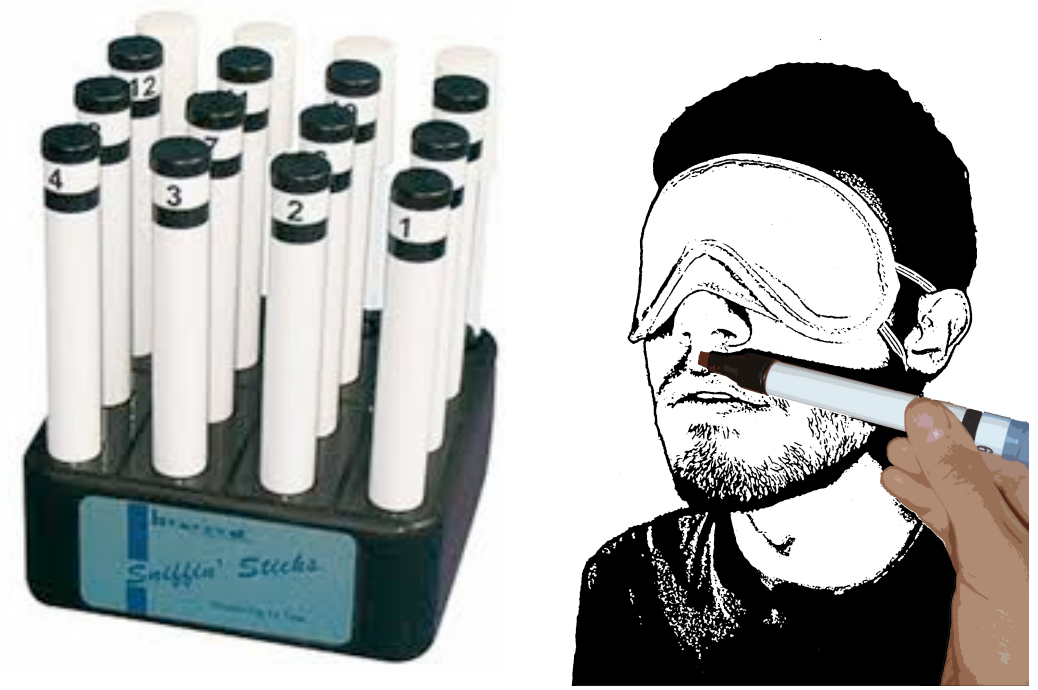

Figure 2. The Sniffin' Sticks. Adapted from Guarneros, Hummel, Martinez-Gomez, \& Hudson, 2009).

\section{Odor identification}

The 'Sniffin' Sticks' multiple force choice identification test was primarily developed for clinicians (Hummel et al., 1997). The test consists of 16 famil- 
iar odorants - orange, peppermint, turpentine, cloves, leather, banana, garlic, rose, fish, lemon, coffee, anise, cinnamon, liquorice, apple, and pineapple with an equal intensity magnitude and hedonic tone. A criterion for the inclusion of an odor in the test set was a familiarity rating of $\geq 89 \%$, a mean identifiably rating of $\pm 25 \%$, a mean intensity rating of $\pm 25 \%$, and an identification performance rate of $\geq 80 \%$. The Sniffin' Sticks are presented with the odors in felt-tip pens (see Figure 2). The cap is removed by the experimenter. Each odor is presented with four verbal descriptors (i.e., one target and three lures) and the subject is instructed to choose the label that best matches the specific odor from the provided list of alternatives.

\section{The Scandinavian Odor Identification Test (SOIT)}

The Scandinavian Odor Identification Test consists of 16 odor stimuli specifically chosen to fit the Scandinavian population: almond (bitter), ammonia, anise, apple, cinnamon, clove, juniper berry, lilac, lemon, orange, peppermint, pine-needle, tar, vanilla, vinegar, and violet. The selection of odors is empirically based on their identifiably, the perceived familiarity, intensity, and pleasantness. All odors are considered as predominantly olfactory stimulants and provide a good basis to for determining olfactory status. In analogy with the Sniffin' Sticks, each stimulus is presented in conjunction with four force-choice response alternatives in order to minimize the cognitive demands (see Table 3). The response alternatives were chosen based on a confusion matrix of identification responses. The SOIT has been demonstrated to constitute a valid and reliable test of odor identification ability (Nordin et al., 1998).

The odor identification test used in Betula is a modified version of the SOIT comprising 13 odors. Vinegar, tar, and peppermint were removed from the stimuli original test set due to their trigeminal qualities. Also, the response alternatives were changed in order to avoid ceiling effects. The stimulus order was randomized between subjects by randomly assigning one out of ten different stimuli to each subject. 
Table 3. The modified version of the SOIT used in the Betula project (Nordin et al., 1998). Targets (bolded text) and distractors.

\begin{tabular}{llll}
\hline Peppermint & Almond(bitter) & Acetone & Ammonia \\
Rose & Cherry & Violet & Vanilla \\
Anise & Vinegar & Honey & Ginger \\
Apple & Lily & Violet & Vanilla \\
Oregano & Clove & Almond (bitter) & Cinnamon \\
Cinnamon & Clove & Ginger & Leather \\
Pine Needle & Gasoline & Juniper berry & Turpentine \\
Lilac & Rose & Lily & Jasmine \\
Orange & Tar & Lemon & Honey \\
Cherry & Strawberry & Orange & Lemon \\
Vanilla & Coconut & Strawberry & Jasmine \\
Eucalyptus & Pine needle & Camphor & Oregano \\
Gasoline & Tar & Leather & Turpentine \\
& & & \\
\hline
\end{tabular}

\section{Hierarchical regression models}

Across Studies I-III, we employed hierarchical regression models to analyze both cross-sectional and longitudinal data. Hierarchical regression is a type of multiple regression technique used to explain variation in a dependent (criterion) variable from multiple independent variables. This is an effective statistical technique to use in order to identify relationships among variables while controlling for variations from other variables. One of the advantages with hierarchical regression modeling is that it can investigate relationships between variables that reside at different hierarchical levels as well as relationships within a particular level (Hofmann, 1997). Also, hierarchical regression analysis permits statistical control of variables in order to study the 
unique influences of a certain factor (e.g., ApoE4, BDNF) on a trait (e.g., odor functions). There are several statistical techniques to assess change. Using hierarchical regression for testing hypotheses about the effects of background variables on individual change is a good way of discovering correlates of change, that is factors that influence the rate of change (Bryk \& Raudenbush, 1987). In Study III we employed hierarchical regression modeling to analyze change in performance between two measurement occasions since it is also a suitable technique for non-experimental data (such as the Betula project) including both continuous (i.e. olfaction and cognition) and dichotomous (i.e., age and genotype) factors. 


\section{Overview of studies}

\section{Study I}

Hedner, M., Larsson, M., Arnold, N., Zucco, G.M., \& Hummel, T. (2010). Cognitive factors in odor detection, odor discrimination, and odor identification tasks. Journal of Clinical and Experimental Neuropsychology, 32(10), 1062-1067.

\section{Aim}

The main aim of Study I was to determine the relative predictive value of demographic and cognitive factors in odor detection, odor discrimination, and odor identification.

\section{Background}

In order to identify a specific odor one needs to know its semantic label. There is evidence supporting the notion that odor identification and semantic memory draw on similar cognitive abilities (Economou, 2003; Larsson et al., 2000; Larsson et al., 2004). However, it is still unclear to what extent performance in other olfactory tasks shares variance with cognitive abilities. In the assessment of odor quality discrimination abilities, the participant is instructed to detect similarities and differences between odorants. Hence, a discrimination task should put demands on processes that draw on executive functions, in that they require an ability to form a transient representation of a target odor and to use this representation for comparison and subsequent selection of the target odor from distractors. In addition, olfactory threshold assessment may also entail discrimination between stimuli (i.e., to differentiate a target from a blank).

\section{Method}

\section{Participants}

The study comprised 170 participants (106 females and 64 males), ranging between 30 to 87 years. All participants were in good health, without any 
complaints of olfactory dysfunction, or any history of ENT pathology.

\section{Measurements}

All olfactory testing was done using the "Sniffin" Sticks" test battery (Burghart, Wedel, Germany). The "Sniffin' Sticks" is a normated test set assessing olfactory function (Hummel, Kobal, Gudziol, \& Mackay-Sim, 2007). The examination involved tests of phenylethyl alcohol odor thresholds, odor discrimination, and odor identification.

The cognitive tests consisted of the Digit Span Backward test, used as an index of executive functioning. A verbal fluency and two tests on general knowledge were used as indices for semantic memory. Also, recall and recognition tests were included to assess episodic memory.

\section{Statistical analyses}

Three separate hierarchical multiple regression analyses were carried out in order to determine the relative influence of different cognitive domains on the respective olfactory task: odor threshold, odor discrimination, and odor identification. All three criteria variables included the same blocks of predictors. The first block consisted of demographic factors (age and sex), and the second block consisted of the cognitive predictors (executive function, semantic memory, and episodic memory).

\section{Results}

The results showed that young age and female sex predicted olfactory sensitivity. However, none of the cognitive predictors shared significant variance with threshold performance. Age, executive function, and semantic memory were significant predictors of odor discrimination. Odor identification performance was predicted by age, executive functioning (the Digit Span Backward test), and proficiency in semantic memory. Episodic memory performance was unrelated to all three olfactory measures (see Table 4).

\section{Conclusion}

The main conclusion from Study I was that cognitive factors influence odor discrimination and identification proficiency, although no such influence was observed for the olfactory threshold test. The findings indicate that odor discrimination and odor identification represent more complex processed tasks than assessment of olfactory sensitivity. 


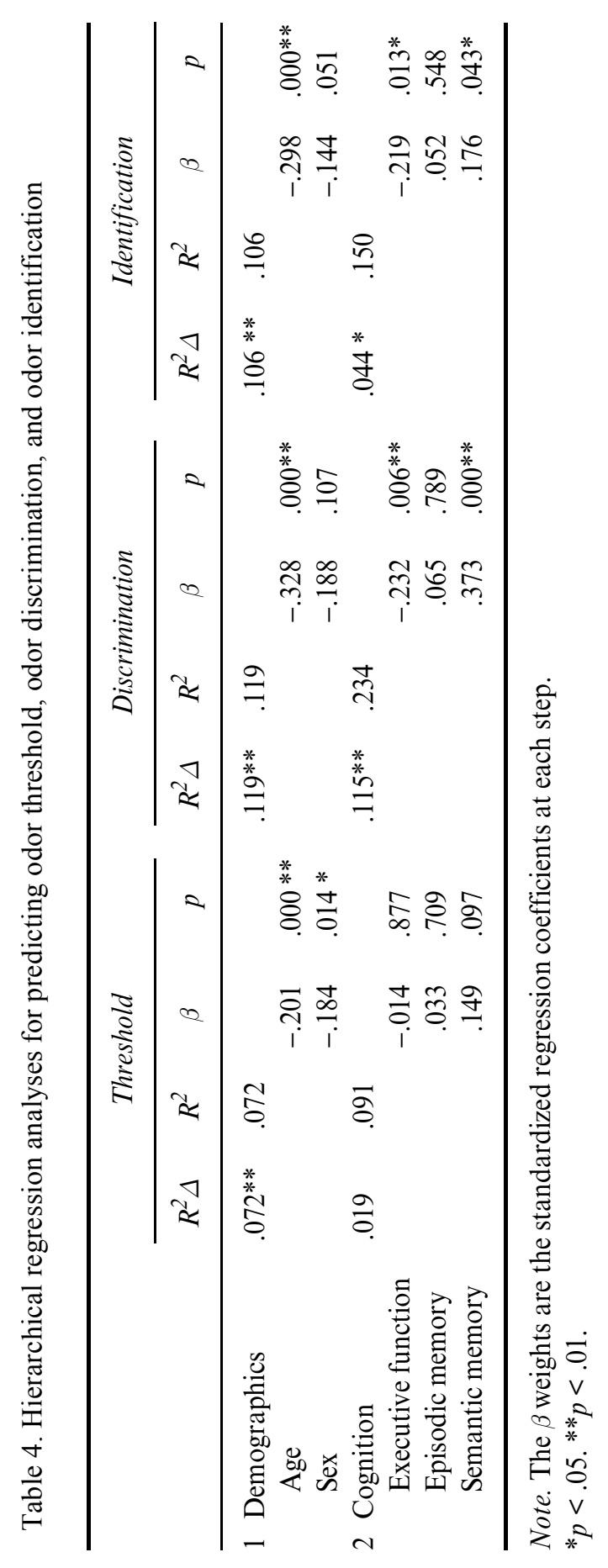




\section{Study II}

Olofsson, J.K., Nordin, S., Wiens, S., Hedner, M., Nilsson, L.-G., \& Larsson, M. (2010). Odor identification impairment in carriers of ApoEvarepsilon 4 is independent of clinical dementia. Neurobiology of Aging, 31(4), 567-577.

\section{Aim}

The main aim of Study II was to investigate a potential influence of the Ap$\mathrm{oE}$ gene on olfactory function after controlling for health status, cognitive factors, and dementia diagnosis.

\section{Background}

Research has shown that the ApoE gene is a strong risk factor for $\mathrm{AD}$ (Corder et al., 1996; Poirier et al., 1993). In addition, olfactory impairments have been observed in pre-clinical AD subjects (Doty et al., 1987; Larsson et al., 1999; Murphy et al., 1999). Hence, it is of interest to investigate whether the ApoE4 influences olfactory performance in non-demented adults and to evaluate whether a potential olfactory deficit in ApoE $\varepsilon 4$ carriers is influenced by pre-diagnostic dementia.

\section{Method}

\section{Participants}

All data derived from the Betula longitudinal prospective cohort study. The study included 1236 participants (564 female and 672 male) that had been genotyped for ApoE and completed the MMSE, odor identification, and vocabulary tests at both third and fourth wave of testing. Among the participants, $30 \%$ carried at least one $\varepsilon 4$ allele. Also, at the time of testing, 24 participants were diagnosed with current dementia and 42 participants were classified with pre-diagnostic dementia as they received a dementia diagnoses five years later.

\section{Measurements}

The participants' health status had been assessed through interviews and questionnaires. The MMSE test was added in order to control for general cognitive status. A vocabulary test was used to control for the influence of semantic ability on individual differences in odor identification. Odor identification was measured by SOIT, a 13-item multiple-choice identification test comprising everyday odors. 


\section{Statistical analysis}

In order to explore the unique and relative contribution of each factor on odor identification ability, a set of hierarchical regression analysis was performed. In the first analysis, eight blocks was added to the model: demographics (age, sex, and education), genetics (ApoE ع4 and ApoE ع2), cognition (vocabulary and MMSE), health, current dementia, pre-diagnostic dementia, the interaction between age and ApoE4, and the interaction between age and ApoE $\varepsilon 4$. In the second analysis, nine blocks was added to the model: demographics (age, sex, and education), cognition (vocabulary and MMSE), health, current dementia, ApoE $\varepsilon 4 \times$ current dementia, prediagnostic dementia, ApoE $\varepsilon 4 \times$ pre-diagnostic dementia, ApoE $\varepsilon 2$ and Ap$\mathrm{oE} \varepsilon 4$.

\section{Results}

The predictor variables accounted for $21.3 \%$ of the explanatory variance in olfactory identification performance. The main finding of Study II was an interaction between age and ApoE $\varepsilon 4$, such that an $\varepsilon 4$ presence was associated with a more pronounced olfactory impairment in older adults (see Figure 3 ). Intriguingly, this effect was not driven by pre-clinical dementia.

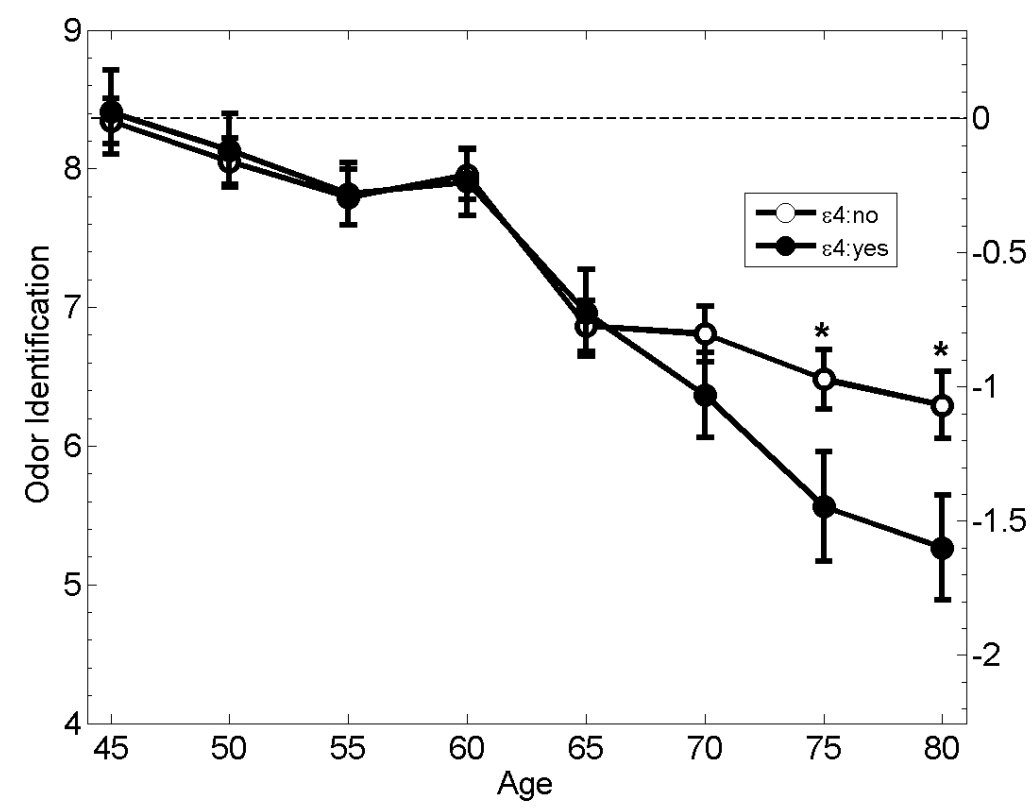

Figure 3. Odor identification performance as a function of age and ApoE $\varepsilon 4$ status. 


\section{Conclusion}

The ApoE $\varepsilon 4$ has a negative influence on olfactory function but only in old age. Importantly, the negative effect is present although dementia conversion is controlled for, at least with a five-year follow-up interval.

\section{Study III}

Hedner, M., Nilsson, L., Olofsson, J.K., Bergman, O., Eriksson, E., Nyberg, L., \& Larsson, M. (2010). Age-related olfactory decline is associated with the BDNF val66met polymorphism: evidence from a population-based study. Frontiers in Aging Neuroscience, 2(24), 1-7.

\section{Aim}

The overall aim of Study III was to investigate the effects of BDNF val66met on odor identification decline over a five-year interval in young and old age.

\section{Background}

The BDNF gene supports neuronal survival, transmission, and synaptic plasticity in the central nervous system (Poo, 2001). One variant of the BDNF gene, val66met, modulates individual differences in human cognition and olfactory function (Egan et al., 2003; Erickson et al., 2008; Harris et al., 2005; Miyajima et al., 2008). A knock-out mouse model has suggested that an absence of BDNF and its receptor TkrB results in olfactory impairment (Bath et al., 2008). However, no previous study has addressed potential effects of the val66met on human olfactory function.

\section{Method}

\section{Participants}

Subjects tested at the third and fourth wave in the Betula project participated in the study. Only subjects that had been genotyped for the BDNF and had completed the vocabulary and olfactory tests were included in the study. In addition, subjects diagnosed with Parkinson's disease or Alzheimer's disease, had a MMSE score below 24 across the two test occasions, and exhibiting a decrease of the MMSE score by three points or more between the two test occasions were removed from the sample. The final sample comprised 836 cognitively intact subjects (447 females and 389 males). 
The subjects were grouped according to genotype: val/val homozygous carriers $(\mathrm{n}=536)$, and met carriers (val/met heterozygous carriers + and met $/ \mathrm{met}$ homozygous carriers; $n=300$ ). To investigate the combined effects of age and BDNF genotype, the participants were divided into two age groups: middle-aged subjects ranging from 45 to 65 years and old subjects ranging from 70 to 90 years of age.

\section{Measurements}

A modified version of the SOIT (Nordin et al., 1998) was used to assess olfactory identification performance. The test consists of 13 odor stimuli specifically chosen to fit a Scandinavian population. A 30-item multiplechoice synonym test (SRB) was used to assess verbal knowledge. In addition, health factors known to affect olfactory function negatively, such as diabetes, cardiovascular disorders, and ENT disorders were controlled for.

\section{Statistical analysis}

A hierarchical regression model comprised of six separate blocks was used. Olfactory identification at five-year follow-up was selected as the criterion measure. The blocks consisted of: the olfactory identification scores at baseline, demographic variables (age, sex, and years of formal education), health-related predictors (diabetes, cardiovascular disorders, and ENT disorders), semantic memory (i.e., vocabulary), the BDNF val66met genotype (i.e., the val/val homozygotes and the met carriers,), and finally, the interaction between age and BDNF val66met.

\section{Results}

The predictor variables altogether accounted for $19.7 \%$ of the explanatory variance in odor identification change from initial testing. The significant predictors were: odor identification proficiency at baseline, lower age, high education, and female sex. The BDNF val66met gene polymorphism alone did not predict odor identification proficiency at follow-up, although the interaction between age and val66met showed a highly significant contribution for olfactory decline (see Figure 4).

A closer inspection of the interaction revealed that the BDNF val66met had a selective effect in the older age cohort, such that older val/val carriers displayed a significantly larger olfactory decline than the older met carriers. Remarkably, no age-related decline in olfactory performance occurred in the older age group among the met carriers. 


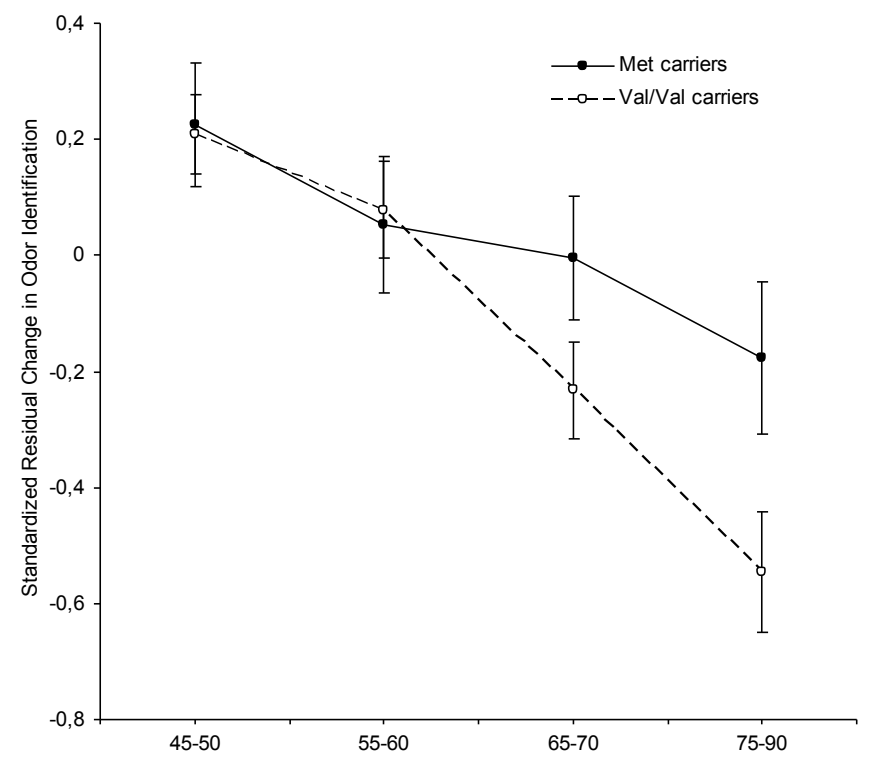

Figure 4. Change in odor identification score $(m e a n \pm S E)$ from baseline to follow-up as a function of age and BDNF val66met status.

\section{Conclusion}

The BDNF val66met polymorphism moderates age-related decline in olfactory identification. In middle-aged subjects, no effect of BDNF val66met was observed, however, old val homozygote carriers displayed a larger olfactory decline than the met carriers. 


\section{Discussion}

The current thesis investigated the relative influence of various demographic, cognitive, and genetic factors on olfactory functions. The main findings of the studies in this thesis can be summarized as follows:

1. Chronological age had a negative impact across all olfactory tests (odor threshold, odor discrimination, and odor identification) (Study I, II, III). There was a female advantage in odor identification assessed by the SOIT, although no sex difference was observed in the Sniffin Sticks' identification test. Also, women had a more sensitive sense of smell as determined by odor threshold measurements (Study I).

2. Cognitive abilities have a significant influence on higher order olfactory functions (Study I, II, III). Semantic memory proficiency and executive functioning were related to odor discrimination and odor identification performance. No cognitive influence was observed for measurements of olfactory threshold (Study I).

3. The ApoE- $\varepsilon 4$ allele was associated with odor identification deficits among elderly participants in a sample of community-dwelling adults. Intriguingly, the negative ApoE- $\varepsilon 4$ effect on olfactory proficiency was independent by clinical dementia conversion within five years (Study II).

4. The BDNF val66met polymorphism moderated the magnitude of the age-related decline in olfactory functioning. Specifically, olfactory decline was larger among older val carriers than for the met carriers (Study III).

Below, some of the obtained results will be highlighted and discussed in relation to previous research findings. I will also address methodological considerations together with some potential problems with genetic association studies. 


\section{Influences of demographic variables on olfactory function}

In the present studies, several demographic factors predicted olfactory ability. These variables can be conceived as reasonable estimates for other possible influential variables, such as life-style factors and social status.

\section{Sex}

As noted above, sex influences olfactory functioning, such that females outperform men in most tasks (Brand \& Millot, 2001). In Study I, the sex variable was reliable only for threshold performance, indicating that females had higher odor sensitivity than males. For both odor discrimination and odor identification no sex effects were observed. The former finding corroborates previous work (Öberg et al., 2002), suggesting that sex has little or no impact on odor discrimination performance. Regarding odor identification, the sex factor fell short from significance $(\mathrm{p}=.051)$, although, the results indicated that females had a slight advantage over men. However, it should be noted that sex was significantly correlated with the TDI-score, suggesting that sex has an effect on general olfactory ability. The TDI-score is an olfactory composite, based on the sum of threshold, discrimination, and identification scores.

In contrast, Study II showed that female sex predicted successful odor identification performance. Also, sex was negatively correlated with odor identification performance at baseline and five-year follow-up in Study III, indicating that females outperformed males. In addition, when baseline performance was partialled out from odor identification performance at follow-up, sex affected the rate of decline such that males declined more than females over the five-year interval. Previous research has found a larger and earlier age-related decline in males for odor identification performance, whereas the decline for females occurs at an older age (Ship et al., 1996). In addition, olfactory dysfunction in older age occurs more often in males than in females (Murpy et al., 2002).

There are several potential explanations for the female superiority in olfactory performance. It has been proposed that the sex difference is inborn or an early developmental sexually dimorphic trait (Ship \& Weiffenbach, 1993). Thus, sex differences may be due to anatomical variations in the structure of the nasal airways, olfactory neural pathways, or in the endocrine system (Brand \& Millot, 2001). Another explanation is that females outperform males in different verbal tasks and that this superiority is reflected in odor identification performance (Larsson et al., 2004). Other possible reasons 
could be that males and females differ in the degree to which they have experienced or learned various odors (Brand \& Millot, 2001).

\section{Education}

Years of formal education were positively related to odor identification across studies. In Study III, less years of education was related to faster olfactory decline over a five-year interval. Previous findings have demonstrated that the association between age-related decline and education is depending upon the specific cognitive domain (Ardila, 2000). Few studies have investigated the effect of education in olfactory performance. Results from this thesis suggest that high education exerts a positive influence on olfactory functions. As earlier commented on in the Introduction section, education may serve as an indirect measure of the reserve capacity (Stern, 2006), such that education could increase brain reserve capacity by increasing synaptic density, which in turn may delay the onset of dementia with four to five years.

In Study I, the level of education of the subjects was not available and could not be controlled for. Hypothetically, a high educational level may result in a superior strategic processing in an olfactory task. For example, in multiplechoice odor identification tasks, such as the SOIT or the Sniffin' Sticks (Hummel et al., 1997; Nordin et al., 1998), the same odor labels are sometimes provided for several items, either as the target odor or as a distractor. If orange has been targeted in a previous odor item, a subject with higher strategic processing abilities may exclude orange as a potential correct label next time it appears in the test.

\section{Health factors}

As reported from previous literature, health status has a large impact on olfactory ability (Deems et al., 1991; Dileo \& Amedee, 1994; Le Floch et al., 1993; Murphy et al., 2002; Weinstock et al., 1993). Nasal and sinus disease, diabetes, head trauma, stroke, epilepsy, are few examples of the different disease conditions that affect olfactory function. The Betula project includes assessments of a variety of diseases. In Study II, only diabetes and neurological disorder were related to odor identification after controlling for age, sex, education, ApoE, and cognitive measures. Inconsistent with previous evidence (Deems et al., 1991), head injury was not related to odor identification. Also, smoking had no impact on odor identification. In Study III, only cardiovascular disease, diabetes, and ENT disorders were included in the analyses. Cardiovascular disease and diabetes were selected since they were significantly correlated with odor identification in Study II. In addition, ENT disorders were included since these conditions are known to affect olfactory 
function (Brämerson et al., 2004; Deems et al., 1991). However, none of these disorders exerted an influence on olfactory decline. Notably, the absence of disease effects on odor identification could be related to that age was controlled for before the health block was added to the regression models.

Although several health factors were taken into consideration in the present studies there may be other diseases secondary to aging, not included in the analyses, that could affect the results. The term successful aging is conceptualized as elderly people in absence of disease and disability, with maintenance of high physical and cognitive function, and sustained engagement in social and productive activities (Rowe \& Kahn, 1997). Previous literature has found that successfully aged participants screened for medical health and cognitive deficits perform at the same level as young in detection sensitivity (Nordin et al., 2012). Thus, present age effects on odor detection, discrimination and identification may be overestimated due to secondary conditions in aging, such as health aspects, that were not taken into consideration in the studies.

\section{Age}

As reported above, aging takes a toll on olfactory functions, this was also demonstrated across the three studies. In Study I, older age was negatively related to all olfactory tasks: threshold, discrimination, and identification. Thus, the present results corroborate previous findings that aging affects both sensory and more complex odor functions (Larsson, 1997). It should be noted that health factors and educational background were not controlled for in Study I that may affect olfactory function and reduce the impact of age. As noted above, a subject's health status may boost the age-related impairments in olfactory function (Nordin et al., 2012). Likewise, when educational background is controlled for, the impact of age in cognitive performance diminishes (Ardila, 2000). Thus, the influence of age is most likely overestimated in Study I.

Further, it is important to note that not only was age a strong negative predictor for olfactory function in general, but also for the rate of decline in particular (Study III).

\section{Influences of cognitive factors on olfactory tasks}

Since olfactory measures are used in clinical settings it is of importance to determine the potential influence of cognitive factors. The take home message from Study I is that an individual's cognitive profile exerts a significant 
influence on higher-order olfactory functions. Odor threshold was not related to any of the cognitive composites, suggesting that this task mainly reflect sensory processes. Also, the results question the notion of discrimination as primarily a sensory driven task. Both semantic memory and executive functions were reliable predictors of odor quality discrimination. As discussed above, the shifting from one presented odor to another and a continuous updating with a new olfactory representation could explain why quality discrimination taps executive functioning (Miyake et al., 2000). Also, the positive semantic influence on discrimination performance is consistent with previous findings showing that the labeling of target odors (i.e., verbal processing) enhances discrimination ability. However, it is important to note that the Digit Span Backwards may not be an ideal index of executive functioning.

As reported earlier, executive functioning also predicted odor identification performance (Dulay et al., 2008). Given that odor discrimination ability and odor identification are two olfactory tasks that are highly correlated (de Wijk \& Cain, 1994), it is not surprising that they load on similar cognitive components. Although cued odor identification poses lower cognitive demands than free identification as the search process for the label is bypassed, the subject still has to decide which of the provided alternatives that best corresponds to the presented odor. The cognitive tasks only accounted for a part (4-11\%) of the variation in more complex olfactory tests. Other influential factors could be health status (i.e., olfactory-related diseases), educational level and/or biological variables. Unfortunately, these factors were not available in Study I.

Odor identification was the only available olfactory task in the Betula project at the time Study II and Study III were carried out. For both studies a vocabulary task was included in the regression models in order to control proficiency in naming ability that may provide an aid in identifying the odors by name. Study II corroborates previous findings that semantic ability plays a significant role in the identification of odors (Larsson, 1997). However, in Study III, semantic ability at baseline did not predict odor identification decline over a five-year period. Thus, controlling for age, low semantic ability impairs odor identification performance cross-sectionally but has no effect on the change of odor identification performance.

\section{ApoE and odor identification}

The results from Study II indicate that olfactory performance in older carriers of the ApoE- $\varepsilon 4$ allele was significantly impaired as compared to middleage carriers and older non-carriers. This effect was independent of a preclin- 
ical AD diagnosis within five years after assessment. In addition, the $\varepsilon 4$ allele was associated with conversion to dementia and cognitive performance (assessed by the MMSE) at a five-year follow-up. However, the effect of the $\varepsilon 4$ allele on odor identification performance was not driven by these factors since the effect remained after statistical control of the MMSE and a dementia diagnosis five year later. As noted, AD is associated with olfactory dysfunction (Nordin \& Murphy, 1998; Nordin et al., 1997). In addition, olfactory impairments have been observed also in MCI patients that received an AD diagnosis within two years (Bacon et al., 1998, Tabert et al., 2005). Given that the ApoE gene is related to AD as well (Bertram, 2004), it could be argued that the obtained effect of ApoE on odor identification in the elderly is driven by an impending development AD. Although the sample in Study II is screened for cognitive dysfunction as well as a dementia diagnosis five years prior to testing, research suggests that preclinical markers are present more than five years before the actual dementia diagnosis (Amieva et al., 2005; Snowdon, Greiner, \& Markesbery, 2000). However, since current and preclinical dementia did not mediate the affect of ApoE $\varepsilon 4$ on odor identification, the relation between the $\varepsilon 4$ allele, odor identification, and dementia appear more complex. Although the ApoE $\varepsilon 4$ allele might cause olfactory deficits by accumulation of amyloid plaques in regions engaged in olfactory processing, this type of AD pathology in the brain does not necessarily lead to a dementia diagnosis (Benett et al., 2006). For example, Davis, Schmitt, Wekstein, and Markesbery (1999) found that autopsied brains of elderly, well-educated individuals with no cognitive impairment had abundant amounts of senile plaques and/or neurofibrillary tangles, suggesting that a large percentage of cognitively intact, relatively well-educated individuals also exhibit numerous degenerative changes. Further, Wilson, Arnold, Schneider, Tang, and Bennett (2007) examined plaques and tangles in postmortem brains where odor identification had been assessed about two years prior to death. Their results indicated that an odor identification deficit in old age partly was due to an accumulation of neurofibrillar pathology in central olfactory regions.

Given that the pre-clinical phase in AD is long, it is yet to be established whether the effect of ApoE $\varepsilon 4$ on odor identification in the elderly may be driven by a preclinical dementia phase longer than five years. Another highly hypothetical explanation could be that a reserve (brain or cognitive) capacity may partly account for the findings in Study II. According to the reserve theory, the clinical expression of AD occurs as the amount of brain damage in specific regions exceeds a critical cognitive threshold and that individual differences in reserve capacity have an impact on the onset of clinical symptoms (Stern, 2009). Although we controlled for educational background, there may be other indices of reserve capacity, such as occupational status, leisure activities, social network and genetic factors. Given that 
cognitive factors are highly heritable, genes may account for one of the factors that contribute to a reserve (Lee, 2003). Thus, the elderly non-demented ApoE $\varepsilon 4$ carriers in Study II may have a high reserve capacity that will mask the clinical manifestations of dementia for more than a five-year period. However, the olfactory deficits could already be present since olfactory deficits are associated with a later risk of cognitive impairment (Graves et al., 1999; Schubert et al., 2008). That is, individuals with severe olfactory dysfunction and without a dementia diagnosis could have a reserve capacity that protects against the clinical manifestations of dementia. If these speculations are valid, then this strengthens the notion that olfactory deficits precede other cognitive symptoms in AD.

\section{BDNF and odor identification}

The main finding of Study III was that the BDNF val66met polymorphism affected the magnitude of the age-related olfactory decline in olfactory functioning. More specifically, BDNF did not affect the rate of decline in middle-aged subjects, whereas older val/val carriers showed a selectively faster olfactory decline. To date, this is the only study that has examined the impact of BDNF on olfactory functioning in humans. However, several studies have investigated the effect of BDNF val66met on cognition and the results are mixed. A recent meta-analysis could not establish any significant influence of BDNF val66met on general cognitive ability, memory, executive function, visual processing skills, or cognitive fluency (Mandelman \& Grigorenko, 2012). However, this meta-analysis did not permit an analysis of age stratifying effects on the association between the BDNF val66met and cognition. Most studies using a sample of young to middle-aged participants report that carriers of the met allele are impaired in cognitive functioning compared to val homozygote carriers (Egan et al., 2003; Hariri et al., 2006; Ho et al., 2006), although others have failed to find an association (Hansell et al., 2007; Nacmias et al., 2004; Strauss et al., 2004). Likewise, findings are mixed regarding the effects of the BDNF on cognition in the elderly. Erickson et al. (2008) and Harris et al. (2005) demonstrated that the val/val genotype exerts negative effects on cognition later in life and promotes a faster rate of cognitive decline. In congruence with our results from Study III, their results suggest that the met allele could work as a protective factor for cognitive decline. However, in contrast to this observation, Tsai et al. (2004) reported that the BDNF val66met played no significant role on cognition in a sample of older men.

One possible explanation of the present findings is that the BDNF gene is proposed to play a role in the neurodegeneration and the birth of new neurons (regeneration), processes vital for plasticity and memory. Several stud- 
ies have observed an altered response of BDNF protein levels or mRNA expression in the hippocampus of AD patients compared to normal controls (Philips et al., 1991; Connor et al., 1997; Hock, Heese, Hulette, Rosenberg, \& Otten, 2000). Such a decrease may be caused by a lack of trophic support and may contribute to the degeneration of specific neuronal populations in the AD affected brain. In addition, Ventriglia et al. (2002) reported a significant higher frequency of homozygotic Val carriers than Met carriers in AD patients compared to normal subjects for the BDNF val66met polymorphism. Importantly, the obtained effects of BDNF on AD are independent from the ApoE e4 allele. However, most studies have failed to find an association between BDNF val66met and AD (Combarros, Infante, Llorca, \& Berciano, 2004; Tsai et al., 2004), suggesting that it is unlikely that the BDNF val66met polymorphism plays a major role in the pathogenesis of AD. In the present work, dementia and preclinical dementia status did not mediate the observed age $\times$ BDNF effect on olfactory decline, suggesting that the olfactory disadvantage among older val/val carriers is unrelated to $\mathrm{AD}$, at least within a five-year period. A study by Lee et al. (2005) observed that the BDNF protein levels in the temporal neocortex were $33 \%$ lower in $\mathrm{AD}$ relative to control brains but neither of the polymorphisms (the val66met and the $\mathrm{C} 270 \mathrm{~T}$ ) were associated with the AD diagnosis. Therefore, no genotype - phenotype relation could be established between the BDNF polymorphisms and BDNF levels of protein. These results suggest that the levels of BDNF protein expressed in the temporal cortex are the principal determinant of the illness rather than the BDNF polymorphisms.

Another, highly speculative explanation could be that the BDNF val66met polymorphism is related to a genetically dependent brain reserve that regulates the number of neurons from birth (Katzman et al., 1998). The BDNF could be one of the modifying genes of this reserve. Then, hypothetically, the val/val carriers may originally have started with less neurons and will consequently meet the threshold for olfactory deficits at an earlier stage. The lack of olfactory decline in the met carriers may then relate to a greater brain reserve among these individuals.

\section{Methodological considerations}

\section{Study designs}

When the effects of aging are investigated, researchers typically compare individuals from different age cohorts (i.e., cross-sectional studies). However, cross-sectional studies are subject to various methodological problems. One of the major concerns when comparing different age cohorts is the gen- 
eration effect. People born and living throughout the same time period share a common history of experiences and events that may be different for people born in another time period. Thus, cross-sectional studies may overestimate the effects of age due to historical influences, such as educational opportunity, cultural factors, and socioeconomic status. Results from the Betula study (Rönnlund, Nyberg, Bäckman \& Nilsson, 2005) focusing on the impact of age on declarative memory with both cross-sectional and longitudinal designs demonstrated that cross-sectional analyses indicated gradual agerelated decrements in episodic memory already at the age of 35 , whereas the longitudinal data revealed no decrements before the age of 60 , also when practice effects were adjusted for. These discrepancies could in part be explained by cohort differences in educational attainment. Since Study II is based on cross-sectional data, the age-related difference between young and old ApoE $\varepsilon 4$ in odor identification should be interpreted with caution until the results can be replicated using a longitudinal design. Another methodological problem concerns selective survival, which affects the generalizability of the findings. The oldest subjects that both survive and stay in the study may represent a highly selected group of high-performing individuals.

Longitudinal designs are also subject to limitations in generalization. Earlier findings have reported that subjects that remain in the study have a higher intelligence and socio-economic status as compared to the drop-outs (Baltes, 1968). Thus, selective attrition in longitudinal study designs may fail to provide a representative study sample. Thus, a longitudinal design may underestimate the true age-effect on cognitive function. This is a notion that needs to be taken into account in Study III that investigates the change in odor identification from wave three to wave four. However, since the odor test was added to the test battery at the third wave of the Betula study, this is a problem for both Study II and Study III. The subjects who remain in the Betula study at wave three may have a higher mean level of performance. However, the drop-out rate in the Betula study is relatively low (Nilsson et al., 1997; Nilsson et al., 2004). Another problem with longitudinal designs is that they are subject to practice effects that also may underestimate the true age effect. However, it should be noted that attempts have been made by the study design used in Betula to control for attrition effects and test-retest effects (Rönnlund et al., 2005). The Betula study has five years between measurement occasions, although the subject becomes more familiar with the task it is unlikely that the participants remember the specific odors and words they encountered in the previous measurement occasion. It could be argued that data from only two time points may be insufficient for assessing change. However, the olfactory data was at the time only available at two measurement occasions in the Betula project. 


\section{Genetic association studies}

Study II and Study III investigate the association between a specific gene and olfactory performance (i.e., association study). A genetic association study explores whether there is a correlation between a specific gene variant and a quantitative trait or disease. Usually a candidate gene is selected based on earlier evidence of its plausible biological relevance and, ideally, if it has a functional significance in the physiology of the trait. With the sequencing of the human genome, the identification of SNPs, and the access to DNA extraction, there has been an enormous increase of association studies, often yielding inconsistent results (Bird, Jarvik, \& Wood, 2001). Many scientists have raised concerns against the use of association studies based on poor study design, insufficient statistical analysis and an over-interpretation of findings (Hirschhorn \& Daly, 2005; Neale \& Sham, 2004). It is also important to note that a finding of an association between a genotype and a variation in cognitive function does not prove that the genetic variation has an impact on brain function or processing. A positive association between an allele and a phenotype can implicate several things: the allele is a causative factor in the phenotype, the association results because another allele is in linkage equilibrium with the tested allele, or simply that the association is an artifact (Goldberg \& Weinberger, 2004).

In an association study, a large genetic effect typically accounts for about $2 \%$ of the individual variance in a specific trait. Because a genetic variant is known to have a small effect on the trait variance, it is important to have a large sample size in order to secure enough power to detect such genetic effects. Also, replication of the results in an independent study population is crucial to avoid false positives and one single report of a positive association between genotype-phenotype should be interpreted with caution. Although the use of association studies have been criticized, the underlying ideas and benefits of these studies are important: it is a fairly cheap and easy method to discover predisposing genes in diseases and phenotypes that could provide clues to treatment and prevention. A single gene does not alone influence a complex behavior but rather an interaction between multiple genes and environmental factors. The association studies (Study II and Study III) in this thesis represent one small step in the search of factors contributing to the integrity of the olfactory sensory system. However, since Study III is the only study, to date, that have investigated the association between BDNF and olfactory function the results should be carefully interpreted until they have been replicated. 


\section{Suggestions for future studies}

The evidence is mixed regarding which cognitive components that are involved in olfactory tasks. Different measures that serve as indexes of olfactory functions may be one of the reasons for the discrepant findings. In Study I, Digit Span Backward served as the only measure for executive functioning. In a future study it would be interesting to replicate the finding, that odor quality discrimination draws on cognitive abilities, by using other tasks that tap executive functions, such as the N-back task (Gevins \& Cutillo, 1993) and the Stroop task (Stroop, 1935). This would strengthen the notion of discrimination of odor quality as a higher-order olfactory task.

As mentioned above, few studies have investigated the impact of age on olfaction in longitudinal study designs. To date, olfactory data from three measurement occasions (waves), spanning over 15 years, is available in the Betula project. It would be highly interesting to create a statistical model for age-related decline over the lifespan using longitudinal data from three waves or more. Such a model could add further knowledge on how olfactory abilities decline over time in comparison to other forms of memory, such as episodic and semantic memory. Also, additional waves of collected data will enable screening the sample for an even longer period of preclinical dementia. A replication of Study II controlling for an impending AD diagnosis within 15 years will add further knowledge to the relation among the ApoE $\varepsilon 4$, olfactory deficits, and AD.

Since this is the first study to establish an association between the BDNF val66met and olfaction in humans, it is important to replicate the findings using independent samples. Also, it is central to establish if the BDNF val66met variants effects olfactory-related brain regions. Future studies on how the BDNF val66met polymorphism is related to the olfactory bulb volume would provide valuable information since the size of the bulb is correlated with olfactory performance (Buschhüter et al. 2008; Seubert et al., 2012).

Due to limitations in association studies, such as poor study design and overinterpretation of findings, these types of studies will probably decrease drastically in the near future. Already, journals demand additional data, such as replication in independent cohorts and/or that supplementary evidence in form of cellular information and/or brain imaging data that can strengthen the association assumption. Other approaches to identify genes that have a significant effect on a trait are linkage analyses and genome-wide association studies (GWAS). A linkage study investigates genetic markers that are inherited within families. Thus, it is a successful method to detect regions involved in recessive and highly penetrant diseases. However, linkage stud- 
ies have less power than association studies to detect weak genetic effects exhibited by the loci involved in complex diseases (Risch \& Merikangas, 1996). GWASs examine the association between several SNPs and common traits, by exploring the entire genome to identify SNPs associated with a trait. In this aspect, the GWAS approach is non-candidate driven. Notably, there are many concerns raised against the GWAS approach as well. It cannot specify which genes that are causal and detecting effects from rare alleles is not possible in GWASs since it requires enormous sample sizes (Nsengiman \& Bishop, 2012. Thus, SNPs discovered by GWASs account for only a small fraction of the genetic variation of complex traits. A novel extension of the GWAS approach is the genome-wide complex trait analysis (GCTA) (Yang et al., 2010). This statistical method is an estimation approach that relates similarity in hundreds of thousands of SNPs to phenotypic similarity in unrelated individuals. A recent study by Deary et al. (2012) estimated the genetic influence on stability and change on intelligence using a variation of GCTA and showed that there is a substantial genetic correlation between intelligence in childhood and in old age. However, GCTAs may underestimate heritability because it is limited to SNPs that have been mapped on the genome and to DNA variants correlated with those SNPs (Plomin, 2012). In future studies, novel methods and technologies in the search for genes involved in stability and change olfactory and cognitive abilities are highly warranted.

\section{Concluding remarks}

The present thesis highlights the impact of demographic, cognitive, and genetic factors on olfactory function. Different olfactory tasks were investigated from both a cognitive and a demographic perspective. Overall, the results showed that a person's genetic and cognitive profile exert an influence on olfactory abilities. Intriguingly, the ApoE and the BDNF gene proved to modulate the effects of age on olfactory function.

The results from this thesis indicate that impairments in frequently used olfactory tests may not only reflect the integrity of the sense of smell but also cognitive deficits. Thus, the current observations are of interest also from a clinical perspective, since disease may have differentiated impact across different olfactory tasks depending on task-specific cognitive demands. 


\section{References}

Albert, M. S., DeKosky, S. T., Dickson, D., Dubois, B., Feldman, H. H., Fox, N. C., Gamst, A., et al. (2011). The diagnosis of mild cognitive impairment due to Alzheimer's disease: recommendations from the National Institute on AgingAlzheimer's Association workgroups on diagnostic guidelines for Alzheimer's disease. Alzheimer's \& dementia: the journal of the Alzheimer's Association, $7(3), 270-279$.

Amieva, H., Jacqmin-Gadda, H., Orgogozo, J.-M., Carret, N. L., Helmer, C., Letenneur, L., Barberger-Gateau, P., et al. (2005). The 9 year cognitive decline before dementia of the Alzheimer type: a prospective population-based study. Brain, 128(5), 1093-1101.

Anstey, K., \& Christensen, H. (2000). Education, Activity, Health, Blood Pressure and Apolipoprotein E as Predictors of Cognitive Change in Old Age: A Review. Gerontology, 46(3), 163-177.

Ardila, A. (2000). Age-Related Cognitive Decline During Normal Aging The Complex Effect of Education. Archives of Clinical Neuropsychology, 15(6), 495513.

Ardila, A., \& Rosselli, M. (1989). Neuropsychological characteristics of normal aging. Developmental Neuropsychology, 5(4), 307-320.

Bacon, A. W., Bondi, M. W., Salmon, D. P., \& Murphy, C. (1998). Very Early Changes in Olfactory Functioning Due to Alzheimer's Disease and the Role of Apolipoprotein E in Olfaction. Annals of the New York Academy of Sciences, 855(1), 723-731. n

Baddeley, A. (2003). Working memory: looking back and looking forward. Nature Reviews Neuroscience, 4(10), 829-839.

Baltes, P. B. (1968). Longitudinal and cross-sectional sequences in the study of age and generation effects. Human Development, 11, 145-171.

Baltes, P. B., \& Lindenberger, U. (1997). Emergence of a powerful connection between sensory and cognitive functions across the adult life span: A new window to the study of cognitive aging? Psychology and Aging, 12(1), 12-21.

Bath, K.G., Mandairon, N., Jing, D., Rajagopal, R., Kapoor, R., Chen, Z., et al. (2008). Variant Brain-Derived Neurotrophic Factor (Val66Met) Alters Adult Olfactory Bulb Neurogenesis and Spontaneous Olfactory Discrimination. Journal of Neuroscience, 28(10), 2383-2393.

Bennett, D. A., Schneider, J. A., Arvanitakis, Z., Kelly, J. F., Aggarwal, N. T., Shah, R. C., \& Wilson, R. S. (2006). Neuropathology of older persons without cognitive impairment from two community-based studies. Neurology, 66(12), $1837-$ 1844.

Bertram, L. (2004). Alzheimer's disease: one disorder, too many genes? Human Molecular Genetics, 13(90001), 135-141.

Bertram, L., McQueen, M. B., Mullin, K., Blacker, D., \& Tanzi, R. E. (2007). Systematic meta-analyses of Alzheimer disease genetic association studies: the AlzGene database. Nature Genetics, 39(1), 17-23. 
Bird, T. D., Jarvik, G. P., \& Wood, N. W. (2001). Genetic association studies Genes in search of diseases. Neurology, 57(7), 1153-1154.

Blair, C. K., Folsom, A. R., Knopman, D. S., Bray, M. S., Mosley, T. H., \& Boerwinkle, E. (2005). APOE genotype and cognitive decline in a middle-aged cohort. Neurology, 64(2), 268-276.

Bouchard, T. J., \& McGue, M. (2003). Genetic and environmental influences on human psychological differences. Journal of Neurobiology, 54(1), 4-45.

Braak, H., \& Braak, E. (1991). Neuropathological stageing of Alzheimer-related changes. Acta Neuropathologica, 82(4), 239-259.

Brand, G., \& Millot, J.-L. (2001). Sex differences in human olfaction: Between evidence and enigma. The Quarterly Journal of Experimental Psychology Section B, 54(3), 259-270.

Breitner, J. C. S., Wyse, B. W., Anthony, J. C., Welsh-Bohmer, K. A., Steffens, D. C., Norton, M. C., Tschanz, J. T., et al. (1999). APOE- $\varepsilon 4$ count predicts age when prevalence of AD increases, then declines The Cache County Study. Neurology, 53(2), 321-321.

Bretsky, P., Guralnik, J. M., Launer, L., Albert, M., \& Seeman, T. E. (2003). The role of APOE- $\varepsilon 4$ in longitudinal cognitive decline MacArthur Studies of Successful Aging. Neurology, 60(7), 1077-1081.

Bryk, A. S., \& Raudenbush, S. W. (1987). Application of hierarchical linear models to assessing change. Psychological Bulletin, 101(1), 147-158.

Brämerson, A., Johansson, L., Ek, L., Nordin, S., \& Bende, M. (2004). Prevalence of Olfactory Dysfunction: The Skövde Population-Based Study. The Laryngoscope, 114(4), 733-737.

Buck, L., \& Axel, R. (1991). A novel multigene family may encode odorant receptors: a molecular basis for odor recognition. Cell, 65(1), 175-187.

Bueller, J., Aftab, M., Sen, S., Gomez-Hassan, D., Burmeister, M., \& Zubieta J. (2006). BDNF Val66Met allele is associated with reduced hippocampal volume in healthy subjects, Biological Psychiatry, 59(9), 812-815

Bunce, D., Fratiglioni, L., Small, B. J., Winblad, B., \& Bäckman, L. (2004). APOE and cognitive decline in preclinical Alzheimer disease and non-demented aging. Neurology, 63(5), 816-821.

Buschhüter, D., Smitka, M., Puschmann, S., Gerber, J. C., Witt, M., Abolmaali, N. D., \& Hummel, T. (2008). Correlation between olfactory bulb volume and olfactory function. NeuroImage, 42(2), 498-502.

Cain, W. S. (1982). Odor identification by males and females: predictions vs performance. Chemical Senses, 7(2), 129-142.

Cain, W. S., \& Potts, B. C. (1996). Switch and Bait: Probing the Discriminative Basis of Odor Identification via Recognition Memory. Chemical Senses, 21(1), 35-44.

Cain, W. S., \& Rabin, M. D. (1989). Comparability of two tests of olfactory functioning. Chemical Senses, 14(4), 479-485.

Calhoun-Haney, R., \& Murphy, C. (2005). Apolipoprotein e4 Is Associated with More Rapid Decline in Odor Identification than in Odor Threshold or Dementia Rating Scale Scores. Brain and Cognition, 58(2), 178-182.

Caselli, R. J., Dueck, A. C., Osborne, D., Sabbagh, M. N., Connor, D. J., Ahern, G. L., Baxter, L. C., et al. (2009). Longitudinal Modeling of Age-Related Memory Decline and the APOE $\varepsilon 4$ Effect. New England Journal of Medicine, 361(3), 255-263.

Christen-Zaech, S., Kraftsik, R., Pillevuit, O., Kiraly, M., Martins, R., Khalili, K., \& Miklossy, J. (2003). Early olfactory involvement in Alzheimer's disease. The Canadian journal of neurological sciences, 30(1), 20-25. 
Cerf-Ducastel, B., \& Murphy, C. (2009). Age-related differences in the neural substrates of cross-modal olfactory recognition memory: An fMRI investigation. Brain research, 1285, 88-98.

Choudhury, E. S., Moberg, P., \& Doty, R. L. (2003). Influences of age and sex on a microencapsulated odor memory test. Chemical Senses, 28(9), 799-805.

Combarros, O., Infante, J., Llorca, J., \& Berciano, J. (2004). Polymorphism at codon 66 of the brain-derived neurotrophic factor gene is not associated with sporadic Alzheimer's disease. Dementia and Geriatric Cognitive Disorders, 18(1), 55-58.

Connor, B., Young, D., Yan, Q., Faull, R. L., Synek, B., \& Dragunow, M. (1997). Brain-derived neurotrophic factor is reduced in Alzheimer's disease. Molecular Brain Research, 49(1-2), 71-81.

Coon, K. D., Myers, A. J., Craig, D. W., Webster, J. A., Pearson, J. V., Lince, D. H., Zismann, V. L., et al. (2007). A high-density whole-genome association study reveals that APOE is the major susceptibility gene for sporadic late-onset Alzheimer's disease. The Journal of clinical psychiatry, 68(4), 613-618.

Corbo, R. M., \& Scacchi, R. (1999). Apolipoprotein E (APOE) allele distribution in the world. Is APOE*4 a 'thrifty' allele? Annals of Human Genetics, 63(4), 301310.

Corder, E. H., Saunders, A. M., Strittmatter, W. J., Schmechel, D. E., Gaskell, P. C., Small, G. W., et al. (1993). Gene dose of apolipoprotein E type 4 allele and the risk of Alzheimer's disease in late onset families. Science, 261(5123), 921923.

Craft, S., Teri, L., Edland, S. D., Kukull, W. A., Schellenberg, G., McCormick, W. C., Bowen, J. D., et al. (1998). Accelerated decline in apolipoprotein E- $\epsilon 4$ homozygotes with Alzheimer's disease. Neurology, 51(1), 149-153.

Craik F.I.M. \& Jennings J.J. 1992. Human memory. In (Eds. Craik F.I.M. \& Salthouse T.A.), Handbook of Aging and Cognition (pp. 51-110). Hillsdale, NJ: Erlbaum.

Cummings, J. L. (2000). Cognitive and behavioral heterogeneity in Alzheimer's disease: seeking the neurobiological basis. Neurobiology of Aging, 21(6), 845861.

Danthiir, V., Roberts, R.D., Pallier, G., \& Stankov, L. (2001) What the nose knows: Olfaction and cognitive abilities. Intelligence, 29(4), 337-361.

Davis, D. G., Schmitt, F. A., Wekstein, D. R., \& Markesbery, W. R. (1999). Alzheimer neuropathologic alterations in aged cognitively normal subjects. Journal of Neuropathology and Experimental Neurology, 58(4), 376-388.

De Wijk, R., \& Cain, W. (1994). Odor quality: Discrimination versus free and cued identification. Attention, Perception, \& Psychophysics, 56(1), 12-18.

De Wijk, R. A. D., \& Cain, W. S. (1994b). Short Note Odor Identification by Name and by Edibility: Life-Span Development and Safety. Human Factors: The Journal of the Human Factors and Ergonomics Society, 36(1), 182-187.

Deary, I. J., Spinath, F. M., \& Bates, T. C. (2006). Genetics of intelligence. European Journal of Human Genetics, 14(6), 690-700.

Deary, I. J., Yang, J., Davies, G., Harris, S. E., Tenesa, A., Liewald, D., Luciano, M., et al. (2012). Genetic contributions to stability and change in intelligence from childhood to old age. Nature, 482(7384), 212-215.

Deems, D. A., Doty, R. L., Settle, R. G., Moore-Gillon, V., Shaman, P., Mester, A. F., Kimmelman, C. P., et al. (1991). Smell and taste disorders, a study of 750 patients from the University of Pennsylvania Smell and Taste Center. Archives of otolaryngology--head \& neck surgery, 117(5), 519-528.

Devanand, D. P., Tabert, M. H., Cuasay, K., Manly, J. J., Schupf, N., Brickman, A. M., Andrews, H., et al. (2010). Olfactory identification deficits and MCI in a 
multi-ethnic elderly community sample. Neurobiology of Aging, 31(9), 15931600.

Devanand, D. P., Michaels-Marston, K. S., Liu, X., Pelton, G. H., Padilla, M., Marder, K., Bell, K., et al. (2000). Olfactory deficits in patients with mild cognitive impairment predict Alzheimer's disease at follow-up. The American Journal of Psychiatry, 157(9), 1399-1405.

Devanand, D. P., Liu, X., Tabert, M. H., Pradhaban, G., Cuasay, K., Bell, K., de Leon, M. J., et al. (2008). Combining Early Markers Strongly Predicts Conversion from Mild Cognitive Impairment to Alzheimer's Disease. Biological Psychiatry, 64(10), 871-879.

Dileo, M. D., \& Amedee, R. G. (1994). Disorders of taste and smell. The Journal of the Louisiana State Medical Society: official organ of the Louisiana State Medical Society, 146(10), 433-437.

Djordjevic, J., Jones-Gotman, M., De Sousa, K., \& Chertkow, H. (2008). Olfaction in patients with mild cognitive impairment and Alzheimer's disease. Neurobiology of Aging, 29(5), 693-706.

Doty, R. L., Applebaum, S., Zusho, H., \& Settle, R. G. (1985). Sex- differences in odor identification ability - a cross-cultural-analysis. Neuropsychologia, 23(5), 667-672.

Doty, R. L., Reyes, P. F., \& Gregor, T. (1987). Presence of both odor identification and detection deficits in Alzheimer's disease. Brain research bulletin, 18(5), 597-600.

Doty, R. L., Shaman, P., Applebaum, S. L., Giberson, R., Siksorski, L., \& Rosenberg, L. (1984). Smell identification ability - changes with age. Science, 226(4681), 1441-1443.

Doty, R., Smith, R., Mckeown, D., \& Raj, J. (1994). Tests of human olfactory function: Principal components analysis suggests that most measure a common source of variance. Attention, Perception, \& Psychophysics, 56(6), 701-707.

Dulay, M. F., Gesteland, R. C., Shear, P. K., Ritchey, P. N., \& Frank, R. A. (2008). Assessment of the influence of cognition and cognitive processing speed on three tests of olfaction. Journal of Clinical and Experimental Neuropsychology, 30(3), 327-337.

Dulay, M. F., \& Murphy, C. (2002). Olfactory acuity and cognitive function converge in older adulthood: support for the common cause hypothesis. Psychology and aging, 17(3), 392-404.

Economou, A. (2003). Olfactory identification in elderly Greek people in relation to memory and attention measures. Archives of Gerontology and Geriatrics, 37(2), $119-130$.

Egan, M. F., Kojima, M., Callicott, J. H., Goldberg, T. E., Kolachana, B. S., Bertolino, A., Zaitsev, E., et al. (2003). The BDNF val66met polymorphism affects activity-dependent secretion of BDNF and human memory and hippocampal function. Cell, 112(2), 257-269.

Ehnholm, C., Lukka, M., Kuusi, T., Nikkilä, E., \& Utermann, G. (1986). Apolipoprotein E polymorphism in the Finnish population: gene frequencies and relation to lipoprotein concentrations. Journal of Lipid Research, 27(3), 227-235.

Engen, T (1987). Remembering odors and their names. American Scientist, 75, $497-$ 503.

Engen, T., \& Ross, B. M. (1973). Long-term memory of odors with and without verbal descriptions. Journal of Experimental Psychology, 100, 221-227.

Erickson, K. I., Kim, J. S., Suever, B. L., Voss, M. W., Francis, B. M., \& Kramer, A. F. (2008). Genetic Contributions to Age-Related Decline in Executive Func- 
tion: A 10-Year Longitudinal Study of COMT and BDNF Polymorphisms. Frontiers in Human Neuroscience, 2, 11.

Finkel, D., Pedersen, N. L., \& Larsson, M. (2001). Olfactory Functioning and Cognitive Abilities A Twin Study. The Journals of Gerontology Series B: Psychological Sciences and Social Sciences, 56(4), 226-233.

Finkel, D., Pedersen, N., McGue, M., \& McClearn, G. (1995). Heritability of cognitive abilities in adult twins: Comparison of Minnesota and Swedish data. Behavior Genetics, 25(5), 421-431.

Finkel, D., Pedersen, N. L., Plomin, R., \& McClearn, G. E. (1998). Longitudinal and cross-sectional twin data on cognitive abilities in adulthood: The Swedish Adoption/Twin Study of Aging. Developmental Psychology, 34(6), 1400-1413.

Finkel, D., Reynolds, C. A., Larsson, M., Gatz, M., \& Pedersen, N. L. (2011). Both odor identification and ApoE- $\varepsilon 4$ contribute to normative cognitive aging. Psychology and aging, 26(4), 872-883.

Frank, R. A., Dulay, M. F., \& Gesteland, R. C. (2003). Assessment of the Sniff Magnitude Test as a clinical test of olfactory function. Physiology \& Behavior, 78(2), 195-204.

Frasnelli, J., Lundström, J., Boyle, J., Djordjevic, J., Zatorre, R., \& Jones-Gotman, M. (2010). Neuroanatomical correlates of olfactory performance. Experimental Brain Research, 201(1), 1-11.

Fratiglioni, L., Launer, L. J., Andersen, K., Breteler, M. M., Copeland, J. R., Dartigues, J. F., Lobo, A., et al. (2000). Incidence of dementia and major subtypes in Europe: A collaborative study of population-based cohorts. Neurologic Diseases in the Elderly Research Group. Neurology, 54(11), 10-15.

Gabrieli, J. D. E. (1998). Cognitive Neuroscience of Human Memory. Annual Review of Psychology, 49(1), 87-115.

Gazzaniga, M.S., Ivry, R., \& Mangun, G.R. (2002). Cognitive Neuroscience: The Biology of the Mind. New York, NY: W.W. Norton.

Gevins, A.S. \& Cutillo, B.C. (1993). Neuroelectric evidence for distributed processing in human working memory. Electroencephalography and Clinical Neurophysiology, 87, 128-143.

Goldberg, T. E. \& Weinberger, D. R. (2004). Genes and the parsing of cognitive processes. Trends in Cognitive Sciences, 8(7), 325-335.

Graves, A. B., Bowen, J. D., Rajaram, L., McCormick, W. C., McCurry, S. M., Schellenberg, G. D., \& Larson, E. B. (1999). Impaired olfaction as a marker for cognitive decline Interaction with apolipoprotein E $\varepsilon 4$ status. Neurology, 53(7), $1480-1480$.

Guarneros, M., Hummel, T., Martinez-Gomez, M., \& Hudson, R. (2009). Mexico City Air Pollution Adversely Affects Olfactory Function and Intranasal Trigeminal Sensitivity. Chemical Senses, 34, 819-826.

Gupta, P., \& Cohen, N. J. (2002). Theoretical and computational analysis of skill learning, repetition priming, and procedural memory. Psychological Review, 109(2), 401-448.

Gylling, H., \& Miettinen, T. A. (1992). Cholesterol absorption and synthesis related to low density lipoprotein metabolism during varying cholesterol intake in men with different apoE phenotypes. Journal of Lipid Research, 33(9), 1361-1371.

Handley, O. J., Morrison, C. M., Miles, C., \& Bayer, A. J. (2006). ApoE gene and familial risk of Alzheimer's disease as predictors of odour identification in older adults. Neurobiology of aging, 27(10), 1425-1430.

Hansell, N. K., James, M. R., Duffy, D. L., Birley, A. J., Luciano, M., Geffen, G. M., Wright, M. J., et al. (2007). Effect of the BDNF V166M polymorphism on 
working memory in healthy adolescents. Genes, Brain and Behavior, 6(3), 260268.

Hariri, A. R., Goldberg, T. E., Mattay, V. S., Kolachana, B. S., Callicott, J. H., Egan, M. F., et al. (2003). Brain-Derived Neurotrophic Factor val66met Polymorphism Affects Human Memory-Related Hippocampal Activity and Predicts Memory Performance. Journal of Neuroscience, 23(17), 6690-6694.

Harris, S. E., Wright, A. F., Hayward, C., Starr, J. M., Whalley, L. J., \& Deary, I. J. (2005). The functional COMT polymorphism, Val $158 \mathrm{Met}$, is associated with logical memory and the personality trait intellect/imagination in a cohort of healthy 79 year olds. Neuroscience letters, 385(1), 1-6.

Hawkes, C. H., Shephard, B. C., \& Daniel, S. E. (1997). Olfactory dysfunction in Parkinson's disease. Journal of Neurology, Neurosurgery \& Psychiatry, 62(5), 436-446.

Herlitz, A., Nilsson, L.-G., \& Bäckman, L. (1997). Gender differences in episodic memory. Memory \& Cognition, 25(6), 801-811.

Herz, R., \& Engen, T. (1996). Odor memory: Review and analysis. Psychonomic Bulletin \& Review, 3(3), 300-313.

Hirschhorn, J. N., \& Daly, M. J. (2005). Genome-wide association studies for common diseases and complex traits. Nature Reviews Genetics, 6(2), 95-108.

Ho, B.-C., Milev, P., O’Leary, D. S., Librant, A., Andreasen, N. C., \& Wassink, T. H. (2006). Cognitive and magnetic resonance imaging brain morphometric correlates of brain-derived neurotrophic factor Val66Met gene polymorphism in patients with schizophrenia and healthy volunteers. Archives of general psychiatry, 63(7), 731-740.

Hock, C., Heese, K., Hulette, C., Rosenberg, C., \& Otten, U. (2000). Regionspecific neurotrophin imbalances in Alzheimer disease: Decreased Levels of brain-derived neurotrophic factor and increased level of nerve growth factor in hippocampus and cortical areas. Archives of neurology, 57(6), 846-851.

Hofmann, D. A. 1997. An overview of the logic and rationale of hierarchical linear models. Journal of Management, 23, 723-744.

Hummel, T., Barz, S., Pauli, E., \& Kobal, G. (1998). Chemosensory event-related potentials change with age. Electroencephalography \& Clinical Neurophysiology: Evoked Potentials, 108(2), 208-217.

Hummel, T., Kobal, G., Gudziol, H., \& Mackay-Sim, A. (2007). Normative data for the "Sniffin' Sticks" including tests of odor identification, odor discrimination, and olfactory thresholds: an upgrade based on a group of more than 3,000 subjects. European Archives of Oto-Rhino-Laryngology, 264(3), 237-243.

Hummel, T., \& Nordin, S. (2005). Olfactory disorders and their consequences for quality of life. Acta Oto-laryngologica, 125(2), 116-121.

Hummel, T., Sekinger, B., Wolf, S. R., Pauli, E., \& Kobal, G. (1997). 'Sniffin" Sticks": Olfactory Performance Assessed by the Combined Testing of Odor Identification, Odor Discrimination and Olfactory Threshold. Chemical Senses, $22(1), 39-52$.

Jönsson, F. U., Tchekhova, A., Lönner, P., \& Olsson, M. J. (2005). A Metamemory Perspective on Odor Naming and Identification. Chemical Senses, 30(4), 353365.

Kaitz, M., Good, A., Rokem, A. M., \& Eidelman, A. I. (1987). Mothers' recognition of their newborns by olfactory cues. Developmental Psychobiology, 20(6), 587591.

Kamboh, M. I., Weiss, K. M., \& Ferrell, R. E. (1991). Genetic studies of human apolipoproteins. XVI. APOE polymorphism and cholesterol levels in the Mayans of the Yucatan Peninsula, Mexico. Clinical Genetics, 39(1), 26-32. 
Kaneda, H., Maeshima, K., Goto, N., Kobayakawa, T., Ayabe-Kanamura, S., \& Saito, S. (2000). Decline in Taste and Odor Discrimination Abilities with Age, and Relationship between Gustation and Olfaction. Chemical Senses, 25(3), 331-337.

Karpa, M. J., Gopinath, B., Rochtchina, E., Wang, J. J., Cumming, R. G., Sue, C. M., \& Mitchell, P. (2010). Prevalence and Neurodegenerative or Other Associations With Olfactory Impairment in an Older Community. Journal of Aging and Health, 22(2), 154-168.

Katoh-Semba, R., Semba, R., Takeuchi, I. K., \& Kato, K. (1998). Age-related changes in levels of brain-derived neurotrophic factor in selected brain regions of rats, normal mice and senescence-accelerated mice: a comparison to those of nerve growth factor and neurotrophin-3. Neuroscience Research, 31(3), 227234.

Katzman, R., Aronson, M., Fuld, P., Kawas, C., Brown, T., Morgenstern, H., Frishman, W., et al. (1989). Development of dementing illnesses in an 80-year-old volunteer cohort. Annals of Neurology, 25(4), 317-324.

Katzman, Robert. (1993). Education and the prevalence of dementia and Alzheimer's disease. Neurology, 43(1), 13-20.

Keller, A. \& Vosshall, L. B. (2004). Human olfactory psychophysics. Current Biology , 14, 875-878.

Keller, A., Zhuang, H., Chi, Q., Vosshall, L. B., \& Matsunami, H. (2007). Genetic variation in a human odorant receptor alters odour perception. Nature, 449(7161), 468-472.

Kjelvik, G., Evensmoen, H. R., Brezova, V., \& Håberg, A. K. (2012). The human brain representation of odor identification. Journal of neurophysiology, 108(2), $645-657$.

Kobal, G., Klimek, L., Wolfensberger, M., Gudziol, H., Temmel, A., Owen, C. M., Seeber, H., et al. (2000). Multicenter investigation of 1,036 subjects using a standardized method for the assessment of olfactory function combining tests of odor identification, odor discrimination, and olfactory thresholds. European Archives of Oto-Rhino-Laryngology, 257(4), 205-211.

Koelega, H. S. (1994). Sex differences in olfactory sensitivity and the problem of the generality of smell acuity. Perceptual and motor skills, 78(1), 203-213.

Konstantinidis, I., Hummel, T., \& Larsson, M. (2006). Identification of unpleasant odors is independent of age. Archives of Clinical Neuropsychology, 21(7), 615621.

Koss, E., Weiffenbach, J. M., Haxby, J. V., \& Friedland, R. P. (1988). Olfactory detection and identification performance are dissociated in early Alzheimer's disease. Neurology, 38(8), 1228-1228.

Kovacs, T. (2004). Mechanisms of olfactory dysfunction in aging and neurodegenerative disorders. Ageing Research Reviews, 3(2), 215-232.

Kovas, Y., \& Plomin, R. (2006). Generalist genes: implications for the cognitive sciences. Trends in Cognitive Sciences, 10(5), 198-203.

Larsson, M. (1997). Semantic Factors in Episodic Recognition of Common Odors in Early and Late Adulthood: a Review. Chemical Senses, 22(6), 623-633.

Larsson, M. (2002). Odor memory: A memory systems approach. In C. Rouby, B. Schaal, D. Dubois, R. Gervais, A. Holley (Eds.), Olfaction, Taste, and Cognition, (pp. 231-245). Cambridge University Press.

Larsson, M., \& Bäckman, L. (1993). Semantic activation and episodic odor recognition in young and older adults. Psychology and Aging, 8(4), 582-588.

Larsson, M., \& Bäckman, L. (1997). Age-related differences in episodic odour recognition: The role of access to specific odour names. Memory, 5(3), 361-378. 
Larsson, M, Finkel, D., \& Pedersen, N. L. (2000). Odor Identification Influences of Age, Gender, Cognition, and Personality. The Journals of Gerontology Series B: Psychological Sciences and Social Sciences, 55(5), 304-310.

Larsson, M., Lövdén, M., \& Nilsson, L.-G. (2003). Sex differences in recollective experience for olfactory and verbal information. Acta Psychologica, 112, 89103.

Larsson, M., Nilsson, L.-G., Olofsson, J., \& Nordin, S. (2004). Demographic and cognitive predictors of odor identification-Evidence from a population-based study. Chemical Senses, 29, 547-554.

Larsson, M, Semb, H., Winblad, B., Amberla, K., Wahlund, L. O., \& Bäckman, L. (1999). Odor identification in normal aging and early Alzheimer's disease: effects of retrieval support. Neuropsychology, 13(1), 47-53.

Lawless, H., \& Engen, T. (1977). Associations to odors: interference, mnemonics, and verbal labeling. Journal of experimental psychology. Human learning and memory, 3(1), 52-59.

Laws, S. M., Hone, E., Gandy, S., \& Martins, R. N. (2003). Expanding the association between the APOE gene and the risk of Alzheimer's disease: possible roles for APOE promoter polymorphisms and alterations in APOE transcription. Journal of Neurochemistry, 84(6), 1215-1236.

Le Floch, J. P., Le Lièvre, G., Labroue, M., Paul, M., Peynegre, R., \& Perlemuter, L. (1993). Smell dysfunction and related factors in diabetic patients. Diabetes care, 16(6), 934-937.

Lee, J. H. (2003). Genetic Evidence for Cognitive Reserve: Variations in Memory and Related Cognitive Functions. Journal of Clinical and Experimental Neuropsychology, 25(5), 594-613.

Lee, J., Fukumoto, H., Orne, J., Klucken, J., Raju, S., Vanderburg, C. R., Irizarry, M. C., et al. (2005). Decreased levels of BDNF protein in Alzheimer temporal cortex are independent of BDNF polymorphisms. Experimental neurology, 194(1), 91-96.

Lehrner, J. P. (1993). Gender differences in long-term odor recognition memory: verbal versus sensory influences and the consistency of label use. Chemical Senses, 18(1), 17-26.

Lehrner, J. P., Glück, J., \& Laska, M. (1999). Odor Identification, Consistency of Label Use, Olfactory Threshold and their Relationships to Odor Memory over the Human Lifespan. Chemical Senses, 24(3), 337-346.

Loo, A. T., Youngentob, S. L., Kent, P. F., \& Schwob, J. E. (1996). The aging olfactory epithelium: Neurogenesis, response to damage, and odorant-induced activity. International Journal of Developmental Neuroscience, 14(7-8), 881-900.

Lu, B., Pang, P. T., \& Woo, N. H. (2005). The yin and yang of neurotrophin action. Nature reviews. Neuroscience, 6(8), 603-614.

Mainland, J., \& Sobel, N. (2006). The Sniff Is Part of the Olfactory Percept. Chemical Senses, 31(2), 181-196.

Mair, R., Capra, C., McEntee, W. J., \& Engen, T. (1980). Odor discrimination and memory in Korsakoff's psychosis. Journal of Experimental Psychology: Human Perception and Performance, 6(3), 445-458.

Mandelman, S. D., \& Grigorenko, E. L. (2012). BDNF Val66Met and cognition: all, none, or some? A meta-analysis of the genetic association. Genes, Brain and Behavior, 11(2), 127-136.

Mesholam, R. I., Moberg, P. J., Mahr, R. N., \& Doty, R. L. (1998). Olfaction in neurodegenerative disease: a meta-analysis of olfactory functioning in Alzheimer's and Parkinson's diseases. Archives of neurology, 55(1), 84-90. 
Matarazzo, J. D., \& Herman, D. O. (1984). Relationship of Education and IQ in the WAIS-R Standardization Sample. Journal of Consulting and Clinical Psychology, 52(4), 631-34.

Mitro, S., Gordon, A. R., Olsson, M. J., \& Lundström, J. N. (2012). The smell of age: perception and discrimination of body odors of different ages. PloS one, 7(5), e38110.

Miwa T, Furukawa M, Tsukatani T, Costanzo RM, Di- Nardo LJ, Reiter ER. (2001). IMpact of olfactory impairment on quality of life and disability. Archives of Otolaryngology-Head \& Neck Surgery, 127(5), 497-503.

Miyajima, F., Quinn, J. P., Horan, M., Pickles, A., Ollier, W. E., Pendleton, N., \& Payton, A. (2008). Additive effect of BDNF and REST polymorphisms is associated with improved general cognitive ability. Genes, Brain and Behavior, 7(7), 714-719.

Miyake, A., Friedman, N. P., Emerson, M. J., Witzki, A. H., Howerter, A., \& Wager, T. D. (2000). The unity and diversity of executive functions and their contributions to complex "Frontal Lobe" tasks: a latent variable analysis. Cognitive psychology, 41(1), 49-100.

Morgan, C. D., Nordin, S., \& Murphy, C. (1995). Odor identification as an early marker for Alzheimer's disease: Impact of lexical functioning and detection sensitivity. Journal of Clinical and Experimental Neuropsychology, 17(5), 793803.

Mortimer, J. A., \& Graves, A. B. (1993). Education and other socioeconomic determinants of dementia and Alzheimer's disease. Neurology, 43(8), 39-44.

Murphy, C. (1999). Loss of olfactory function in dementing disease. Physiology \& behavior, 66(2), 177-182.

Murphy, C,. Bacon, A. W., Bondi, M. W., \& Salmon, D. P. (1998). Apolipoprotein E status is associated with odor identification deficits in nondemented older persons. Annals of the New York Academy of Sciences, 855, 744-750.

Murphy, C., Cain, W. S., Gilmore, M. M., \& Skinner, R. B. (1991). Sensory and semantic factors in recognition memory for odors and graphic stimuli: elderly versus young persons. The American journal of psychology, 104(2), 161-192.

Murphy, C., Gilmore, M. M., Seery, C. S., Salmon, D. P., \& Lasker, B. R. (1990). Olfactory thresholds are associated with degree of dementia in Alzheimer's disease. Neurobiology of aging, 11(4), 465-469.

Murphy, C., Morgan, C. D., Geisler, M. W., Wetter, S., Covington, J. W., Madowitz, M. D., Nordin, S., et al. (2000). Olfactory event-related potentials and aging: normative data. International journal of psychophysiology: official journal of the International Organization of Psychophysiology, 36(2), 133-145.

Murphy, C., Nordin, S., Wijk, R. A. de, Cain, W. S., \& Polich, J. (1994). Olfactoryevoked potentials: assessment of young and elderly, and comparison to psychophysical threshold. Chemical Senses, 19(1), 47-56.

Murphy, C., Schubert, C. R., Cruickshanks, K. J., Klein, B. E., Klein, R., \& Nondahl, D. M. (2002). Prevalence of olfactory impairment in older adults. JAMA: The Journal of the American Medical Association, 288(18), 2307-2312.

Nacmias, B., Piccini, C., Bagnoli, S., Tedde, A., Cellini, E., Bracco, L., \& Sorbi, S. (2004). Brain-derived neurotrophic factor, apolipoprotein $\mathrm{E}$ genetic variants and cognitive performance in Alzheimer's disease. Neuroscience Letters, 367(3), 379-383.

Nagel, I. E., Chicherio, C., Li, S., Oertzen, T. V., Sander, T., Villringer, A., et al. (2008). Human Aging Magnifies Genetic Effects on Executive Functioning and Working Memory. Frontiers in Human Neuroscience, $2,1$. 
Nathan, B. P., Nannapaneni, S., Gairhe, S., Nwosu, I., \& Struble, R. G. (2007). The distribution of apolipoprotein $\mathrm{E}$ in mouse olfactory epithelium. Brain research, 1137(1), 78-83.

Neale, B. M., \& Sham, P. C. (2004). The future of association studies: Gene-based analysis and replication. American journal of human genetics, 75(3), 353-362.

Nilsson, L.-G. (2003). Memory function in normal aging. Acta Neurologica Scandinavica, 107, 7-13.

Nilsson, L.-G., Adolfsson, R., Bäckman, L., Cruts, M., Nyberg, L., Small, B. J., \& Van Broeckoven, C. (2006). The influence of apoe status on episodic and semantic memory: Data from a population-based study. Neuropsychology, 20(6), $645-657$.

Nilsson, L. G., Adolfsson, R., Bäckman, L., de Frias, C. M., Molander, B., \& Nyberg, L. (2004). Betula: A prospective cohort study on memory, health and aging. Aging Neuropsychology and Cognition, 11(2-3), 134-148.

Nilsson, L.-G., Bäckman, L., Erngrund, K., Nyberg, L., Adolfsson, R., Bucht, G., Karlsson, S., et al. (1997). The betula prospective cohort study: Memory, health, and aging. Aging, Neuropsychology, and Cognition, 4(1), 1-32.

Nordin, S., Almkvist, O., \& Berglund, B. (2012). Is Loss in Odor Sensitivity Inevitable to the Aging Individual? A Study of "Successfully Aged" Elderly. Chemosensory Perception, 5(2), 188-196.

Nordin, S., Almkvist, O., Berglund, B., \& Wahlund, L. O. (1997). Olfactory dysfunction for pyridine and dementia progression in Alzheimer disease. Archives of neurology, 54(8), 993-998.

Nordin, S., Brämerson, A., Liden, E., \& Bende, M. (1998). The Scandinavian odoridentification test: Development, reliability, validity and normative data. Acta Oto-Laryngologica, 118(2), 226- 234.

Nordin, S., \& Murphy, C. (1996). Impaired sensory and cognitive olfactory function in questionable Alzheimer's disease. Neuropsychology, 10, 113-119.

Nsengimana, J., \& Bishop, D. T. (2012). Design considerations for genetic linkage and association studies. Methods in molecular biology (Clifton, N.J.), 850, 237 262.

Nyberg, L., Bäckman, L., Erngrund, K., Olofsson, U., \& Nilsson, L.-G. (1996). Age Differences in Episodic Memory, Semantic Memory, and Priming: Relationships to Demographic, Intellectual, and Biological Factors. The Journals of Gerontology Series B: Psychological Sciences and Social Sciences, 51B(4), 234-240.

Nyberg, L., Maitland, S. B., Rönnlund, M., Bäckman, L., Dixon, R. A., Wahlin, Å., \& Nilsson, L.-G. (2003). Selective adult age differences in an age-invariant multifactor model of declarative memory. Psychology and Aging, 18(1), 149160.

Olofsson, J. K., Rönnlund, M., Nordin, S., Nyberg, L., Nilsson, L.-G., \& Larsson, M. (2009). Odor Identification Deficit as a Predictor of Five-Year Global Cognitive Change: Interactive Effects with Age and ApoE- $\varepsilon 4$. Behavior Genetics, 39(5), 496-503.

Ott, A., Breteler, M. M. B., van Harskamp, F., Claus, J. J., van der Cammen, T. J. M., Grobbee, D. E., \& Hofman, A. (1995). Prevalence of Alzheimer's disease and vascular dementia: association with education. The Rotterdam study. $B M J$, 310(6985), 970-973.

Pedersen, N. L., Plomin, R., Nesselroade, J. R., \& McClearn, G. E. (1992). A Quantitative Genetic Analysis of Cognitive Abilities During the Second Half of the Life Span. Psychological Science, 3(6), 346-353. 
Petersen, R. C., Smith, G. E., Waring, S. C., Ivnik, R. J., Tangalos, E. G., \& Kokmen, E. (1999). Mild cognitive impairment: clinical characterization and outcome. Archives of neurology, 56(3), 303-308.

Pezawas, L., Verchinski, B. A., Mattay, V. S., Callicott, J. H., Kolachana, B. S., Straub, R. E., Egan, M. F., Meyer-Lindenberg, A, \& Weinberger, D. R. (2004). The Brain-Derived Neurotrophic Factor val66met Polymorphism and Variation in Human Cortical Morphology. The Journal of Neuroscience, 24(45), 10099 10102.

Phillips, H. S., Hains, J. M., Armanini, M., Laramee, G. R., Johnson, S. A., \& Winslow, J. W. (1991). BDNF mRNA is decreased in the hippocampus of individuals with Alzheimer's disease. Neuron, 7(5), 695-702.

Pivac, N., Kim, B., Nedić, G., Joo, Y. H., Kozarić-Kovačić, D., Hong, J. P., \& Muck-Seler, D. (2009). Ethnic Differences in Brain-derived Neurotrophic Factor Val66Met Polymorphism in Croatian and Korean Healthy Participants. Croatian Medical Journal, 50(1), 43-48.

Plomin, R. (2012). Genetics: How intelligence changes with age. Nature, 482(7384), $165-166$.

Pol, H. E. H., Hijman, R., Baaré, W. F. C., Eekelen, S. van, \& Ree, J. M. van. (2000). Odor Discrimination and Task Duration in Young and Older Adults. Chemical Senses, 25(4), 461-464.

Poo, M. (2001). Neurotrophins as synaptic modulators. Nature Reviews Neuroscience, 2(1), 24-32.

Raber, J., Huang, Y., \& Ashford, J. W. (2004). ApoE genotype accounts for the vast majority of AD risk and AD pathology. Neurobiology of aging, 25(5), 641-650.

Rabin, M. (1988). Experience facilitates olfactory quality discrimination. Attention, Perception, \& Psychophysics, 44(6), 532-540.

Rabin, M. D., \& Cain, W. S. (1984). Odor recognition: familiarity, identifiability, and encoding consistency. Journal of experimental psychology. Learning, memory, and cognition, 10(2), 316-325.

Rawson, N. E., Gomez, G., Cowart, B., \& Restrepo, D. (1998). The Use of Olfactory Receptor Neurons (ORNs) from Biopsies to Study Changes in Aging and Neurodegenerative Diseasesa. Annals of the New York Academy of Sciences, 855(1), 701-707.

Raz, N., Rodrigue, K. M., Kennedy, K. M., \& Land, S. (2009). Genetic and vascular modifiers of age-sensitive cognitive skills: Effects of COMT, BDNF, ApoE, and hypertension. Neuropsychology, 23(1), 105-116.

Rebeck, G., Reiter, J. S., Strickland, D. K., \& Hyman, B. T. (1993). Apolipoprotein $\mathrm{E}$ in sporadic Alzheimer's disease: Allelic variation and receptor interactions. Neuron, 11(4), 575-580.

Richardsson, J. T. E., \& Zucco, M. G. (1989). Cognition and olfaction: A review. Psychological Bulletin, 105, 352-360.

Riley, K. P., Snowdon, D. A., \& Markesbery, W. R. (2002). Alzheimer's neurofibrillary pathology and the spectrum of cognitive function: Findings from the Nun Study. Annals of Neurology, 51(5), 567-577.

Risch, N. \& Merikangas, K. (1996). The Future of Genetic Studies of Complex Human Diseases. Science, 273, 1516-17.

Rönnlund, M., Nyberg, L., Bäckman, L., \& Nilsson, L.-G. (2005). Stability, Growth, and Decline in Adult Life Span Development of Declarative Memory: Cross-Sectional and Longitudinal Data From a Population-Based Study. Psychology and Aging, 20(1), 3-18. 
Roses, A. D. (1998). Apolipoprotein E and ALzheimer's Disease: The Tip of the Susceptibility Iceberg. Annals of the New York Academy of Sciences, 855(1), 738-743.

Rowe, J. W., \& Kahn, R. L. (1997). Successful Aging. The Gerontologist, 37(4), 433-440.

Sacks, O. (1986). The Man Who Mistook His Wife for a Hat, and Other Clinical Tales. London: Picador.

Salthouse, T. A. (1994). The aging of working memory. Neuropsychology, 8(4), 535-543.

Salthouse, T. A., Hambrick, D. Z., \& McGuthry, K. E. (1998). Shared age-related influences on cognitive and noncognitive variables. Psychology and Aging, 13(3), 486-500.

Savic, I., Gulyas, B., Larsson, M., \& Roland, P. (2000). Olfactory Functions Are Mediated by Parallel and Hierarchical Processing. Neuron, 26(3), 735-745.

Schaal, B, Montagner, H., Hertling, E., Bolzoni, D., Moyse, A., \& Quichon, R. (1980). Olfactory stimulation in the relationship between child and mother. Reproduction, nutrition, development, 20(3B), 843-858.

Schacter, D. L. (1990). Perceptual Representation Systems and Implicit Memory. Annals of the New York Academy of Sciences, 608(1), 543-571.

Schacter, D. L., \& Tulving, E. (1994). Memory Systems. Cambridge, MA: MIT Press.

Schemper, T., Voss, S., \& Cain, W. S. (1981). Odor Identification in Young and Elderly Persons: Sensory and Cognitive Limitations. Journal of Gerontology, 36(4), 446-452.

Schubert, C. R., Carmichael, L. L., Murphy, C., Klein, B. E. K., Klein, R., \& Cruickshanks, K. J. (2008). Olfaction and the 5-Year Incidence of Cognitive Impairment in an Epidemiological Study of Older Adults. Journal of the American Geriatrics Society, 56(8), 1517-1521.

Segal, N. L., Topolski, T. D., Wilson, S. M., Brown, K. W., \& Araki, L. (1995). Twin analysis of odor identification and perception. Physiology \& behavior, 57(3), 605-609.

Serby, M., Larson, P., \& Kalkstein, D. (1991). The nature and course of olfactory deficits in Alzheimer's disease. The American journal of psychiatry, 148(3), $357-360$.

Seubert, J., Freiherr, J., Frasnelli, J., Hummel, T., \& Lundström, J. N. (2012). Orbitofrontal Cortex and Olfactory Bulb Volume Predict Distinct Aspects of O1factory Performance in Healthy Subjects. Cerebral Cortex.

Ship, J. A., Pearson, J. D., Cruise, L. J., Brant, L. J., \& Metter, E. J. (1996). Longitudinal Changes in Smell Identification. The Journals of Gerontology Series A: Biological Sciences and Medical Sciences, 51A(2), 86-91.

Ship, J. A., \& Weiffenbach, J. M. (1993). Age, Gender, Medical Treatment, and Medication Effects on Smell Identification. Journal of Gerontology, 48(1), 2632.

Simpson, P., Miller, I., Moon, C., Hanlon, A., Liebl, D., \& Ronnett, G. (2002). Atrial natriuretic peptide type $\mathrm{C}$ induces a cell-cycle switch from proliferation to differentiation in brain-derived neurotrophic factor- or nerve growth factorprimed olfactory receptor neurons. Journal of Neuroscience, 22(13), 55365551.

Small, B. J., Graves, A. B., McEvoy, C. L., Crawford, F. C., Mullan, M., \& Mortimer, J. A. (2000). Is APOE- $\varepsilon 4$ a risk factor for cognitive impairment in normal aging? Neurology, 54(11), 2082-2088. 
Small, B. J., Rosnick, C. B., Fratiglioni, L., \& Bäckman, L. (2004). Apolipoprotein E and Cognitive Performance: A Meta-Analysis. Psychology and Aging, 19(4), 592-600.

Snowdon, D. A., Greiner, L. H., \& Markesbery, W. R. (2000). Linguistic Ability in Early Life and the Neuropathology of Alzheimer's Disease and Cerebrovascular Disease: Findings from the Nun Study. Annals of the New York Academy of Sciences, 903(1), 34-38.

Squire, L. R. (1992). Declarative and Nondeclarative Memory: Multiple Brain Systems Supporting Learning and Memory. Journal of Cognitive Neuroscience, 4(3), 232-243.

Stern, Y. (2006). Cognitive Reserve and Alzheimer Disease. Alzheimer Disease \& Associated Disorders, 20(2), 112-117.

Stern, Y. (2009). Cognitive Reserve. Neuropsychologia, 47(10), 2015-2028.

Stevens, J.C., \& Cain,.W.S. (1987).Old-age deficits in the sense of smell as gauged by thresholds, magnitude matching, and odor identification. Psychology and Aging, 2(1), 36-42.

Stevens, J. C., Cain, W. S., \& Burke, R. J. (1988). Variability of olfactory thresholds. Chemical Senses, 13(4), 643-653.

Strauss, J., Barr, C., George, C., Ryan, C., King, N., Shaikh, S., Kovacs, M., et al. (2004). BDNF and COMT polymorphisms. NeuroMolecular Medicine, 5(3), 181-192.

Stroop, J. R. (1935). Studies of interference in serial verbal reactions. Journal of Experimental Psychology, 225, 643-662.

Struble, R. G., Short, J., Ghobrial, M., \& Nathan, B. P. (1999). Apolipoprotein E immunoreactivity in human and mouse olfactory bulb. Neuroscience letters, 267(2), 137-140.

Sunderland, T., Mirza, N., Putnam, K. T., Linker, G., Bhupali, D., Durham, R., Soares, H., et al. (2004). Cerebrospinal fluid $\beta$-amyloid1-42 and tau in control subjects at risk for Alzheimer's disease: The effect of APOE $\varepsilon 4$ allele. Biological Psychiatry, 56(9), 670-676.

Swan, G. E., \& Carmelli, D. (2002). Impaired Olfaction Predicts Cognitive Decline in Nondemented Older Adults. Neuroepidemiology, 21(2), 58-67.

Tabert, M. H., Liu, X., Doty, R. L., Serby, M., Zamora, D., Pelton, G. H., Marder, K., et al. (2005). A 10-item smell identification scale related to risk for Alzheimer's disease. Annals of Neurology, 58(1), 155-160.

Teri, L., Hughes, J. P., \& Larson, E. B. (1990). Cognitive Deterioration in Alzheimer's Disease Behavioral and Health Factors. Journal of Gerontology, 45(2), $58-63$.

Tsai, S.-J., Hong, C.-J., Liu, H.-C., Liu, T.-Y., Hsu, L.-E., \& Lin, C.-H. (2004). Association Analysis of Brain-Derived Neurotrophic Factor Val66Met Polymorphisms with Alzheimer's Disease and Age of Onset. Neuropsychobiology, 49(1), 10-12.

Tsuboi, Y., Wszolek, Z. K., Graff-Radford, N. R., Cookson, N., \& Dickson, D. W. (2003). Tau pathology in the olfactory bulb correlates with Braak stage, Lewy body pathology and apolipoprotein $\varepsilon 4$. Neuropathology and Applied Neurobiology, 29(5), 503-510.

Tulving, E. (2002). Episodic memory: From Mind to Brain. Annual Review of Psychology, 53(1), 1-25.

Wang, J., Eslinger, P. J., Smith, M. B., \& Yang, Q. X. (2005). Functional Magnetic Resonance Imaging Study of Human Olfaction and Normal Aging. The Journals of Gerontology Series A: Biological Sciences and Medical Sciences, 60(4), 510-514. 
Weinstock, R. S., Wright, H. N., \& Smith, D. U. (1993). Olfactory dysfunction in diabetes mellitus. Physiology \& behavior, 53(1), 17-21.

Ventriglia, M., Chiavetto, L., Benussi, L., Binetti, G., Zanetti, O., Riva, M., et al. (2002). Association between the BDNF $196 \mathrm{~A} / \mathrm{G}$ polymorphism and sporadic Alzheimer's disease. Molecular Psychiatry, 7(2), 136-137.

Willander, J., \& Larsson, M. (2007). Olfaction and Emotion: The case of autobiographical memory. Memory \& Cognition, 35, 1659-1663.

Willander, J., \& Larsson, M. (2006). Smell your way back to childhood: Autobiographical odor memory, Psychnomic Bulletin \& Review, 13, 240-244.

Wilson, R. S., Arnold, S. E., Schneider, J. A., Tang, Y., \& Bennett, D. A. (2007). The relationship between cerebral Alzheimer's disease pathology and odour identification in old age. Journal of Neurology, Neurosurgery \& Psychiatry, $78(1), 30-35$.

Wilson, R. S., Arnold, S. E., Tang, Y., \& Bennett, D. A. (2006). Odor Identification and Decline in Different Cognitive Domains in Old Age. Neuroepidemiology, 26(2), 61-67.

Wilson R. S., Schneider, J. A., Arnold, S. E., Tang, Y., Boyle, P. A., \& Bennett, D. A (2007). OLfactory identification and incidence of mild cognitive impairment in older age. Archives of General Psychiatry, 64(7), 802-808.

Wise, P., Bien, N., \& Wysocki, C. (2008). Two Rapid Odor Threshold Methods Compared to a Modified Method of Constant Stimuli. Chemosensory Perception, 1(1), 16-23.

Wysocki, C. J., \& Gilbert, A. N. (1989). National Geographic Smell Survey: Effects of Age Are Heterogenous. Annals of the New York Academy of Sciences, $561(1), 12-28$.

Yang, J., Benyamin, B., McEvoy, B. P., Gordon, S., Henders, A. K., Nyholt, D. R., Madden, P. A., et al. (2010). Common SNPs explain a large proportion of the heritability for human height. Nature genetics, 42(7), 565-569.

Zatorre, R. J., \& Jones-Gotman, M. (1991). Human Olfactory Discrimination After Unilateral Frontal or Temporal Lobectomy. Brain, 114A(1), 71-84.

Zelinski, E. M., Gilewski, M. J., \& Schaie, K. W. (1993). Individual differences in cross-sectional and 3-year longitudinal memory performance across the adult life span. Psychology and aging, 8(2), 176-186.

Zhang, M., Katzman, R., Salmon, D., Jin, H., Cai, G., Wang, Z., Qu, G., et al. (1990). The prevalence of dementia and Alzheimer's disease in Shanghai, China: Impact of age, gender, and education. Annals of Neurology, 27(4), 428-437.

Zigova, T., Pencea, V., Wiegand, S. J., \& Luskin, M. B. (1998). Intraventricular Administration of BDNF Increases the Number of Newly Generated Neurons in the Adult Olfactory Bulb. Molecular Cellular Neuroscience, 11(4), 234-245.

Öberg, C., Larsson, M., \& Bäckman, L. (2002). Differential sex effects in olfactory functioning: The role of verbal processing. Journal of the International Neuropsychological Society, 8(5), 691-698. 